\title{
Model Test Research on the End Bearing Behavior of the Large-Diameter Cast-in-Place Concrete Pile for Jointed Rock Mass
}

\author{
Jingwei Cai, ${ }^{1}$ Aiping Tang, ${ }^{1}$ Xinsheng Yin, ${ }^{2}$ Xiaxin Tao, ${ }^{1}$ and Shibo Tao ${ }^{1}$ \\ ${ }^{1}$ Civil and Engineering School, Harbin Institute of Technology, Harbin 150001, China \\ ${ }^{2}$ Civil and Engineering School, Jilin Jianzhu University, Changchun 130118, China \\ Correspondence should be addressed to Jingwei Cai; cjw850607@126.com
}

Received 13 July 2016; Revised 29 September 2016; Accepted 19 October 2016

Academic Editor: Cheng-Tang Wu

Copyright (c) 2016 Jingwei Cai et al. This is an open access article distributed under the Creative Commons Attribution License, which permits unrestricted use, distribution, and reproduction in any medium, provided the original work is properly cited.

\begin{abstract}
For large-diameter, cast-in-place concrete piles, the end bearing capacity of a single pile is affected by discontinuous surfaces that exist in natural rock masses when the bearing layer of the pile end is located in the rock layer. In order to study the influence of the jointed dip angle on the bearing characteristics of the pile end, the discrete element models are adopted to simulate the mechanical characteristics of the jointed rock masses, and the model tests of the failure mode of the jointed rock masses were also designed. The results of the numerical calculations and modeling tests show that the joints, which have a filtering effect on the internal stress of the bedrock located at the pile end, change the load transferring paths. And the failure mode of the jointed rock foundation also changes as jointed dip angle changes. The rock located at the pile end generally presents a wedge failure mode. In addition, the $Q-S$ curves obtained by model tests show that the ultimate end bearing capacity of a single pile is influenced by the jointed dip angle. The above results provide an important theoretical basis for how to correctly calculate end resistance for a cast-in-place concrete pile.
\end{abstract}

\section{Introduction}

To improve the end bearing capacity of large-diameter castin-place concrete piles, it is best to select rock strata as the bearing stratum at the pile end. Researches by Serrano and Olalla [1, 2], Yang and Yin [3], Saada et al. [4], and Imani et al. [5] focused on the rock mass according to the Hoek-Brown failure criterion, which is applied for intact rocks. However, in practical engineering, the most natural rock masses are made of rock blocks and discontinuous surfaces, and the discontinuity plays an important role in rock deformation and the failure mechanism. However, conducting a destructive test to determine the ultimate bearing capacity of a single pile in a prototype test is cost prohibitive, which limits researchers' ability to collect sufficient experimental data in order to better understand bearing behavior. This is especially true when the bedrock of the pile end is discontinuous, in which case, even with a large field test, it is very difficult to gather data necessary for a qualitative analysis of the influence of jointed dip angles on bearing capacity. Thus, research needs to focus on how to correctly calculate the end bearing resistance of a single pile in a jointed rock foundation.

At present, some researchers conducted studies on the bearing behavior of jointed rock masses. Reik and Zacas [6] studied the strength and deformation characteristics of jointed media in true triaxial compression. Yang et al. [7] carried out uniaxial compression test of shale rock and found that there are three kinds of failure modes for the jointed rock and that a change in the dip angle caused changes in the failure modes. Yang et al. [8] conducted a uniaxial compression test using marble specimens with prefabricated joints and described the relationship between the dip angle and the failure mode of nonconsecutive jointed rock. Mas Ivars et al. [9] described a new approach they called synthetic rock mass modeling for simulating the mechanical behavior of a jointed rock mass. Zhou et al. [10] fabricated rocklike materials containing multiple fissures under uniaxial compression to further research the effects of preexisting 
fissures on mechanical properties and crack coalescence of rock. Compared with previous experiments, they found five types of cracks, including wing cracks, quasi-coplanar secondary cracks, oblique secondary cracks, out-of-plane tensile cracks, and out-of-plane shear cracks and ten types of crack coalescence. Gao and Kang [11] demonstrated a numerical analysis using a discrete element method simulation for the jointed rock masses. And the numerical results indicate that fracture intensity has no significant influence on the residual strength of jointed rock masses, independent of confining conditions. Cao et al. [12] combined similar material testing and discrete element numerical method (PFC2D) to study the peak strength and failure characteristics of rock-like materials with multifissures. The failure mode can be classified into four categories: mixed failure, shear failure, stepped path failure, and intact failure. And the results show that the peak strength and failure modes in the numerically simulated and experimental results are in good agreement. Yang et al. [13] studied the relationship between the 3D morphological characteristics and the peak shear strength for jointed rock. And a new peak shear strength criterion for rock joints was proposed using two 3D morphological parameters. Furthermore, the calculated peak strengths using the proposed criterion match well with the observed values. Huang et al. [14] did a series of uniaxial compression tests to research the effects of preexisting fissures on the mechanical properties and crack coalescence process for rock-like material with two unparallel fissures. And the strength and deformability characteristics of rock with preexisting fissures are governed by cracking behavior.

Although the above research results could be applied to a jointed rock mass, the results are different from the jointed rock foundation of a pile end that supports the vertical load from the pile and thus produces different failure modes. Kulhawy and Goodman [15] put forward that the spacing of horizontal and vertical joints is the essential factors in the ultimate pile end resistance. Benmokrane et al. [16] conducted a rock-socketed pile model test and illustrated that when weak intercalated layers exist within the rock mass, the ultimate end bearing capacity is influenced by the different jointed dip angles. Maghous et al. [17] assessed the load bearing capacity of rock foundations resting on a regularly jointed rock and considered the rock matrix and the joints separately. They then compared the obtained results with those derived through considering the jointed rock mass as a homogenized medium. Sutcliffe et al. [18] analyzed the bearing capacity of rock masses containing one to three sets of closely spaced joints. Halakatevakis and Sofianos [19] used a distinct element code to analyze a series of jointed rock samples containing one to three joint sets with various spacing and dip angles and concluded that the strength of the models was independent of the joint spacing. Yu [20] proposed the extended finite element method (XFEM), a numerical method for analyzing discontinuous rock masses that is very convenient for preprocessing. In this model, discontinuities, such as joints, faults, and material interfaces, are contained in the elements, so the mesh can be generated without taking into account the existence of discontinuities. Hossein et al. [21] used distinct element method to build a numerical model to evaluate bearing capacity of strip footing rested on anisotropic discontinuous rock mass. And the results show that the failure mechanism of rock mass depended on both geometrical parameters of joint sets and strength parameters of rock mass.

In order to study the relationship between jointed dip angles and the end bearing characteristics of a single pile, we use discrete element models to simulate the mechanical characteristics of jointed bedrock with different inclination angles. The laboratory model tests are designed to analyze the failure modes, cracking mechanism, and variations in the ultimate end bearing capacity when the jointed dip angles and jointed numbers are changed. The results obtained from the model tests are compared with the numerical analysis results to verify the correctness of the related theory of the failure mechanism of the jointed rock mass.

\section{Numerical Analysis of the Failure Mode}

2.1. The Theoretical Basis of Discrete Element Method. The failure modes of the jointed rock foundation are simulated with different jointed dip angles according to the discrete element method. Discrete element method (DEM) was firstly proposed by Cundall in 1971. This method is based on the discrete characteristics of material itself to establish numerical model. It shows great superiority in simulating discrete material.

The discrete element program PFC (particle flow code), which can simulate circular particle movement and interaction, is adopted to simulate the failure. The interactional force of particles is calculated according to Newton's second law and the contact law of force. Discrete element analysis considers the following interactional forces: (1) the force of gravity; (2) the contact force between particles and between particles and walls; (3) the frictional force between particles and between particles and walls. The calculated results are compared to the experimental results in order to verify the correctness of the theoretical analysis.

The basic motion equation of the discrete element is built by dynamic relaxation method as

$$
m \ddot{x}(t)+c \dot{x}(t)+k x(t)=f(t),
$$

where $m$ is the quality of a unit; $x(t)$ is the displacement of a unit; $t$ is the time; $c$ is the viscous damping coefficient; $k$ is the stiffness coefficient; $f(t)$ is the external load of a unit. Equation (1) can be changed into the following form as equation (2) by using the central difference method.

$$
\begin{aligned}
& \frac{m[x(t+\Delta t)-2 x(t)+x(t-\Delta t)]}{\left(\Delta t^{2}\right)} \\
& +\frac{c[x(t+\Delta t)-x(t-\Delta t)]}{\left(2 \Delta t^{2}\right)}=f(t),
\end{aligned}
$$

where $t$ is the calculating time step and (3) can be obtained by changing (2):

$$
\begin{aligned}
& x(t+\Delta t) \\
& =\frac{\left\{\left(\Delta t^{2}\right) f(t)+(c \Delta t / 2-m) x(t-\Delta t)+\left[2 m-k(\Delta t)^{2}\right] x(t)\right\}}{(m+c \Delta t / 2)} .
\end{aligned}
$$




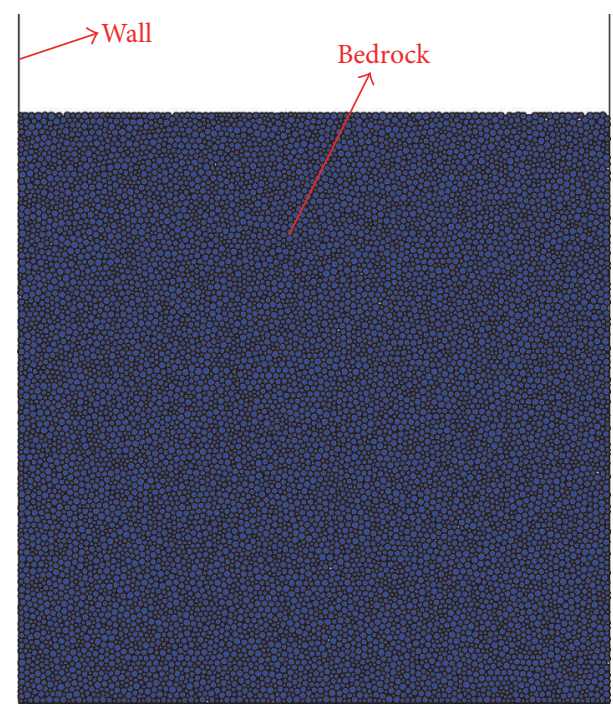

(a) The intact rock model

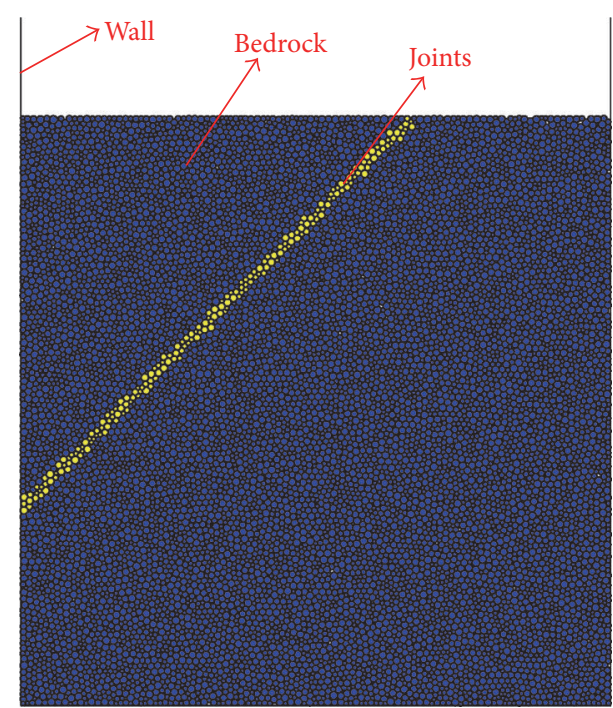

(b) The jointed rock model

FIGURE 1: The rock model.

The velocity and acceleration of the particles in the time of $t$ can be obtained by bringing $x(t+\Delta t)$ into the following two equations:

$$
\begin{aligned}
\dot{x}(t) & =\frac{[x(t+\Delta t)-x(t-\Delta t)]}{2(\Delta t)}, \\
\ddot{x}(t) & =\frac{[\dot{x}(t+\Delta t)-2 x(t)+x(t-\Delta t)]}{(\Delta t)^{2}} .
\end{aligned}
$$

So it can be seen that the central difference method is used in discrete element method. It is an explicit solution which does not require the solution of a large matrix and saves the computing time. And this method can be used to solve some nonlinear problems.

\subsection{Setup Simulation Models and Determination of the Basic} Parameters. The model is made up of an end-closed cylindrical container filled with well-compacted round particles and a pipe-shaped model pile. The soil model with a width of $10 B(\mathrm{~W})$ and a height of $10 B$ is used, where $B$ is the pile diameter and is equal to $50 \mathrm{~mm}$. And the pile length is $20 \mathrm{~mm}$. The roughness of the pile surface can be set up to simulate the friction coefficient.

The relative parameters of particles are shown in Table 1 obtained by general triaxial test of particle flow code. A set of parameters, which can reflect the macroscopic mechanical behavior of rock mass, are obtained by constantly adjusting the microparameters. And this set of parameters could reflect the strength and deformation characteristics of the rock materials. The rock models, which are composed of balls with the diameters uniformly varying between $2 \mathrm{~mm}$ and $3 \mathrm{~mm}$, contained intact rock models and the jointed rock models with the dip angles of $0^{\circ}, 10^{\circ}, 30^{\circ}, 45^{\circ}, 60^{\circ}, 75^{\circ}$ and $90^{\circ}$, respectively.
TABLE 1: The model parameters of pile particles and soil particles.

\begin{tabular}{lccc}
\hline Parameters & $\begin{array}{c}\text { Rock } \\
\text { particles }\end{array}$ & $\begin{array}{c}\text { Joints } \\
\text { particles }\end{array}$ & $\begin{array}{c}\text { Pile } \\
\text { particles }\end{array}$ \\
\hline $\begin{array}{l}\text { Friction coefficient } \\
\text { Normal contact stiffness } \\
(\mathrm{MPa} / \mathrm{m})\end{array}$ & 0.7 & 0.3 & 0.7 \\
$\begin{array}{l}\text { Shear contact stiffness } \\
(\mathrm{MPa} / \mathrm{m})\end{array}$ & 1200 & 100 & 2000 \\
$\begin{array}{l}\text { Parallel-bond normal } \\
\text { stiffness }(\mathrm{MPa} / \mathrm{m})\end{array}$ & 400 & 100 & 2000 \\
$\begin{array}{l}\text { Parallel-bond shear } \\
\text { stiffness }(\mathrm{MPa} / \mathrm{m})\end{array}$ & $2 e 4$ & $1 e 4$ & $1 e 8$ \\
$\begin{array}{l}\text { Density }\left(\mathrm{kg} / \mathrm{m}^{3}\right) \\
\text { Normal bond stress }(\mathrm{MPa})\end{array}$ & 500 & 500 & 1000 \\
\begin{tabular}{l} 
Shear bond stress $(\mathrm{MPa})$ \\
\hline
\end{tabular} & 500 & 500 & 1000 \\
\hline
\end{tabular}

The following assumptions are made to simulate the process of pressing the pile: (1) the particle unit is considered elastomer; (2) the contact points between particles allow a certain amount of "overlap"; (3) compared with the particle size of itself, the "overlap" is very small; (4) the particles of rock mass are spherical unit. The boundary condition of rock mass is built through the "wall" module. The functions of the wall include the following two aspects: (1) to reach the specified initial confining pressure or axial pressure; (2) to maintain a certain confining pressure. The rock model is shown in Figure 1. And the crack distribution, the load transfer path, and the displacement field can be obtained from the results of numerical simulation.

2.3. Crack Distribution. It can be seen from Figure 2(a) that in intact rock the crack distribution is basically symmetrical under upper loading. As loading continues, a compaction 

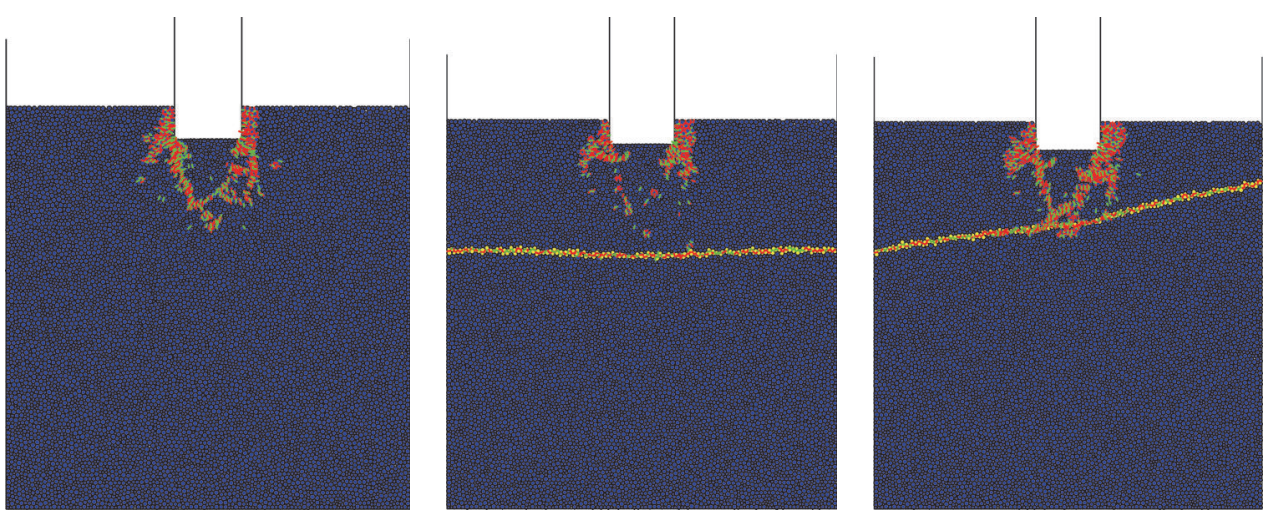

Particles of joints
Particles of rock
Tensile failure of particles
Pressure failure of particles

(a) No joints

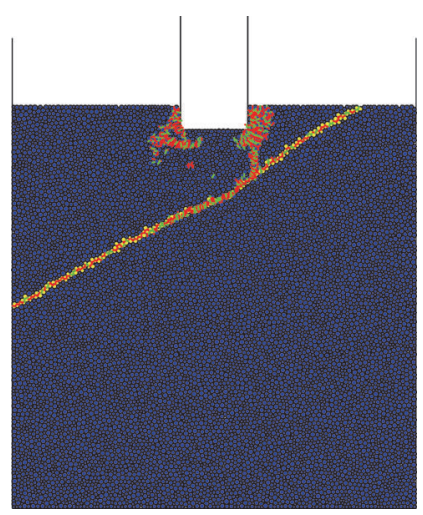

Particles of joints

- Particles of rock

Tensile failure of particles

Pressure failure of particles

(d) $30^{\circ}$
Particles of joints

- Particles of rock

- Tensile failure of particles

Pressure failure of particles

(b) $0^{\circ}$

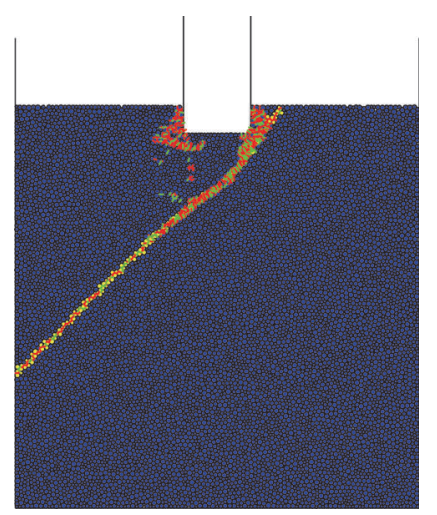

- Particles of joints

- Particles of rock

Tensile failure of particles

- Pressure failure of particles

(e) $45^{\circ}$
- Particles of joints
- Particles of rock
Tensile failure of particles
Pressure failure of particles

(c) $10^{\circ}$

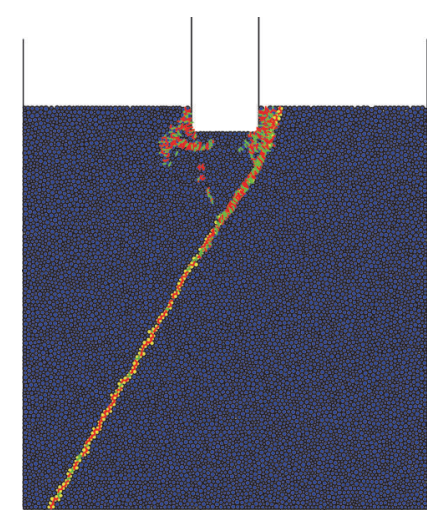

- Particles of joints

- Particles of rock

Tensile failure of particles

- Pressure failure of particles

(f) $60^{\circ}$
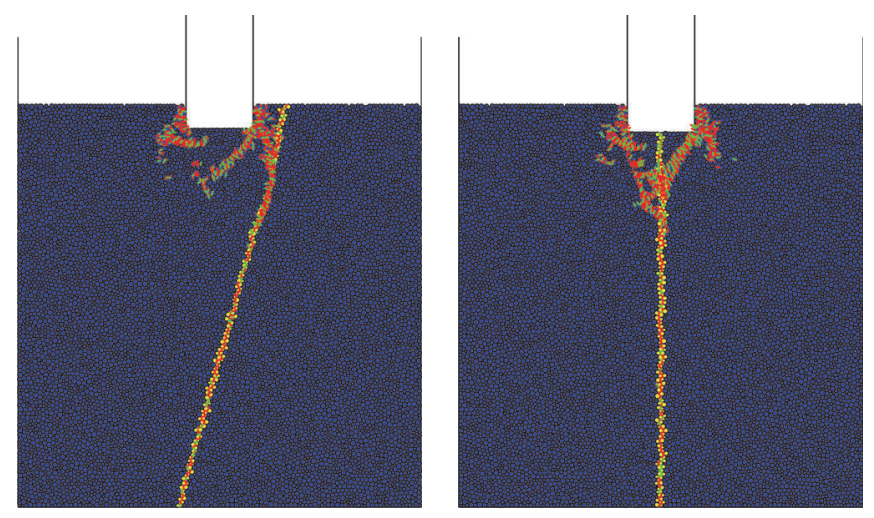

Particles of joints

- Particles of rock

- Tensile failure of particles

- Pressure failure of particles

(g) $75^{\circ}$

Particles of joints

- Particles of rock

- Tensile failure of particles

- Pressure failure of particles

(h) $90^{\circ}$

FIGURE 2: The crack distributions of single-jointed rock mass with different dip angles. 
TABLE 2: Design parameters of the modeling pile and the rock.

\begin{tabular}{lcccc}
\hline The numbers & Material ratios (sand : cement : water) & Pile diameters $(\mathrm{mm})$ & Jointed dip angles & Jointed numbers \\
\hline Group A & $2: 1: 0.6$ & 50 & $0^{\circ} 10^{\circ} 30^{\circ} 45^{\circ} 60^{\circ} 75^{\circ} 90^{\circ}$ & 1 \\
Group B & $3: 1: 0.6$ & 50 & $0^{\circ} 10^{\circ} 30^{\circ} 45^{\circ} 60^{\circ} 75^{\circ} 90^{\circ}$ & 1 \\
Group C & $2: 1: 0.6$ & 50 & $0^{\circ} 10^{\circ} 30^{\circ} 45^{\circ} 60^{\circ} 75^{\circ} 90^{\circ}$ \\
\hline
\end{tabular}

region like a cone will be generated at the pile end, and the cracks next to the compaction region are in a radial distribution. When the jointed dip angles are $0^{\circ}$ and $10^{\circ}$, as shown in Figures 2(b) and 2(c), the cracks are distributed mainly above the jointed layer which reduces the end bearing capacity. When the jointed dip angle is $30^{\circ}$, as shown in Figure 2(d), the cracks are still distributed mainly above the jointed layer. When the value of the angle increases, as shown in Figures 2(e), 2(f), and 2(g), the phenomenon becomes more pronounced. It indicates that the cracks in the rock are distributed mainly in the rock where the loading from the pile end is applied directly and the stress of the bedrock is uneven. The rock is thus identified as anisotropic due to the existence of the joints.

2.4. Load Transferring Path. Figure 3 shows that the existence of the joints, which have a filtering effect on the stress in the bedrock, changes the load transfer path inside the bedrock at the pile end. In order to maintain the stability of the bedrock and avoid dislocation of the joints, the stress used to resist the upper load is reduced, which changes depending on the jointed dip angle. When the dip angle is small $\left(0^{\circ}-30^{\circ}\right)$, the stress delivered from the pile end continues downward at the jointed position, and the stress distribution in the rock mass is the regional average. When the jointed dip angle increases to $45^{\circ}$ to $75^{\circ}$, part of the stress is transferred to restrain the mutual movement of the jointed surfaces in order to ensure the stability of the rock mass. The load at the pile end is still mainly borne by the rock mass above the joint, but it is more obvious for the jointed dip angle of $45^{\circ}$ to $75^{\circ}$. When the jointed dip angle is $90^{\circ}$, the stress is distributed evenly to the two parts by the joint, the distribution of the stress and displacement is symmetrical, and there is no obvious effect on the bearing capacity.

\section{Model Testing}

The spacing of joints in rock mass is usually in meters so that the volume unit becomes very large. Because large-scale mechanical testing is difficult to carry out in rock, it is not realistic to directly measure the mechanical properties of the rock. On the other hand, in situ testing of rock masses has greater ability to produce discreteness in results, so laboratory testing with similar materials could be conducted systematically in order to control the parameters and obtain reasonable mechanical properties. Thus, laboratory testing is widely used for studying the strength, deformation, and failure mechanism of jointed rock masses. In order to analyze the stress, deformation, and failure mechanism of the jointed bedrock more intuitively, a laboratory test was created for a cast-in-place concrete pile to obtain the data regarding different jointed distributions, the ultimate bearing capacity, and the $Q-S$ curves of a single pile.

3.1. The Determination of Experimental Materials. In this test, the pile body is simulated using a solid steel bar with the elastic modulus $E$ of $2.1 e 5 \mathrm{MPa}$, which ensures that the pile will not be destroyed before the destruction of the bedrock. Considering the feasibility of the model test and the limitation of the site, the test uses as the model materials sand, cement, and water mixed to a specific ratio to form a mortar. Mixed ratios of similar materials are obtained by making standard test blocks and measuring the stress-strain curves to ensure that stress-strain curves similar to natural rock could be adopted. In order to determine the most suitable mixed ratios, different ratios were created. At the end, two ratios were selected as most suitable for the test because of their similarity to natural rock (sand : cement : water $=2: 1: 0.6$ and $3: 1: 0.6)$. The uniaxial compressive strength of the prepared materials after 28 days is $6 \mathrm{MPa}$, the unconfined compressive strength $\left(\sigma_{c}\right)$ of the simulated rock material is $6 \mathrm{MPa}$, and the elastic modulus $\mathrm{Er}$ is $608 \mathrm{MPa}$.

\subsection{The Experimental Design}

3.2.1. The Loading Devices. Taking into consideration the influence of pressing the pile into the bedrock, the size of the experimental model was determined to be $500 \mathrm{~mm} * 500 \mathrm{~mm}$ * $500 \mathrm{~mm}$ (length $*$ width $*$ height). So the loading box size was $520 \mathrm{~mm} * 520 \mathrm{~mm} * 520 \mathrm{~mm}$ (length $*$ width $*$ height). Four steel plates' size of $490 \mathrm{~mm} * 490 \mathrm{~mm}$ was used around the testing block to constrain the horizontal displacement. The thickness of the steel plates was $20 \mathrm{~mm}$, and they were fixed by the mutual pulling of long high-strength screws and solid steel squares to provide lateral confinement. The size of the bottom steel plate was $600 \mathrm{~mm} * 600 \mathrm{~mm}$ with a thickness of $20 \mathrm{~mm}$. In order to reduce the friction between the loading box and the testing block, a lubricant was used between the plates and the rock. The loading system is shown in Figure 4 with a maximum measuring range of $200 t$ as the loading device, and the loading box is shown in Figure 5. The designing parameters of the modeling pile and the rock are shown as in Table 2.

3.2.2. The Making of the Jointed Testing Blocks. The jointed testing blocks were created using a cutting method. The positions of the joints were marked on the testing surfaces before cutting. After cutting the joints of the blocks, rubber membranes and rubber bands were used to hold up them in order to ensure the overall stability. Then the rock model 

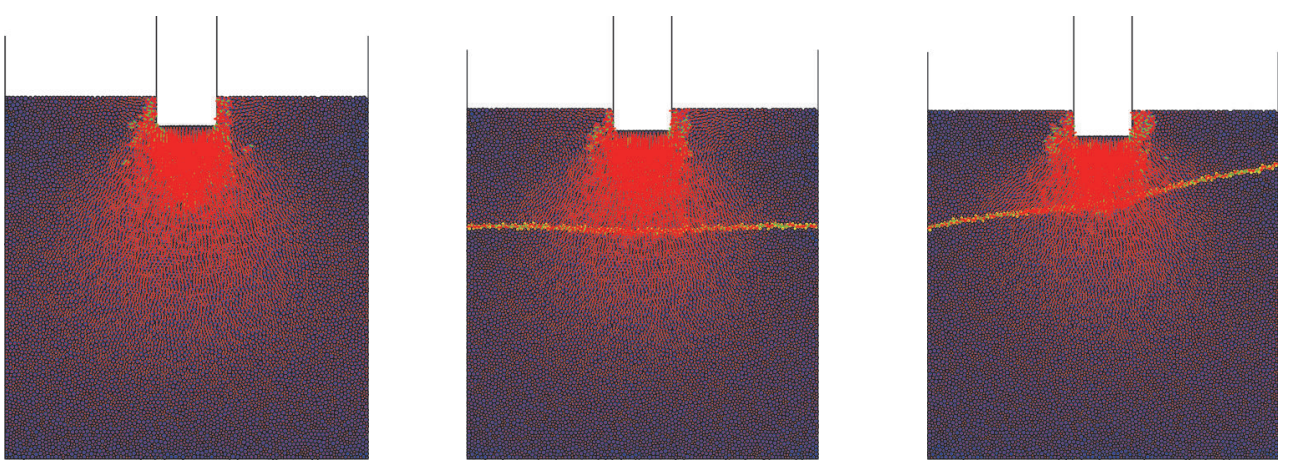

Particles of joints

- Particles of rock

Tensile failure of particles

Pressure failure of particles

$\longrightarrow$ Direction placement for particles

(a) No joints

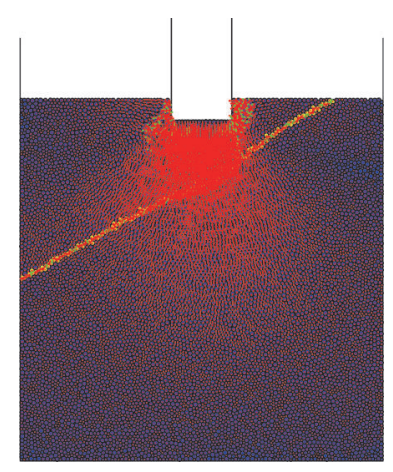

Particles of joints

- Particles of rock

Tensile failure of particles

- Pressure failure of particles

$\longrightarrow$ Direction placement for particles

(d) $30^{\circ}$

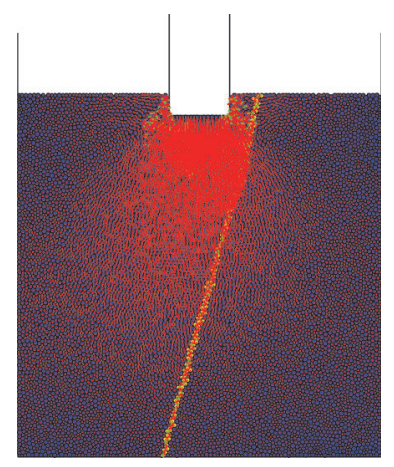

Particles of joints

- Particles of rock

Tensile failure of particles

Pressure failure of particles

$\longrightarrow$ Direction placement for particles

(g) $75^{\circ}$
Particles of joints

- Particles of rock

- Tensile failure of particles

- Pressure failure of particles

$\longrightarrow$ Direction placement for particles

(b) $0^{\circ}$

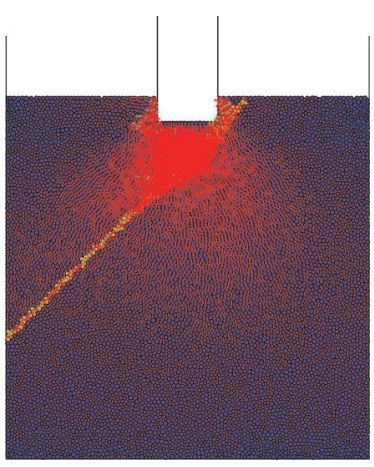

Particles of joints

- Particles of rock

Tensile failure of particles

- Pressure failure of particles

$\longrightarrow$ Direction placement for particles
Particles of joints

- Particles of rock

Tensile failure of particles

- Pressure failure of particles

$\longrightarrow$ Direction placement for particles

(c) $10^{\circ}$

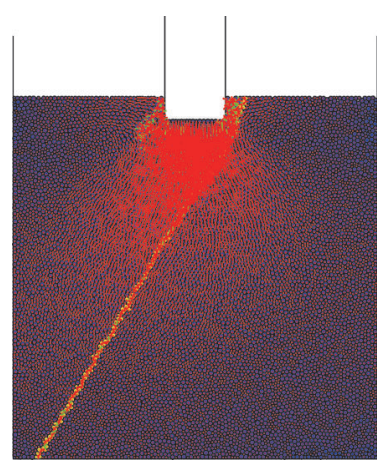

Particles of joints

- Particles of rock

- Tensile failure of particles

- Pressure failure of particles

$\longrightarrow$ Direction placement for particles

(e) $45^{\circ}$

(f) $60^{\circ}$

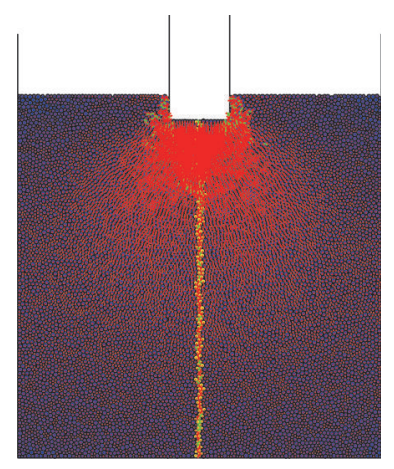

Particles of joints

- Particles of rock

Tensile failure of particles

Pressure failure of particles

$\longrightarrow$ Direction placement for particles

(h) $90^{\circ}$

FIGURE 3: The displacement distributions of single-jointed rock mass with different dip angles. 


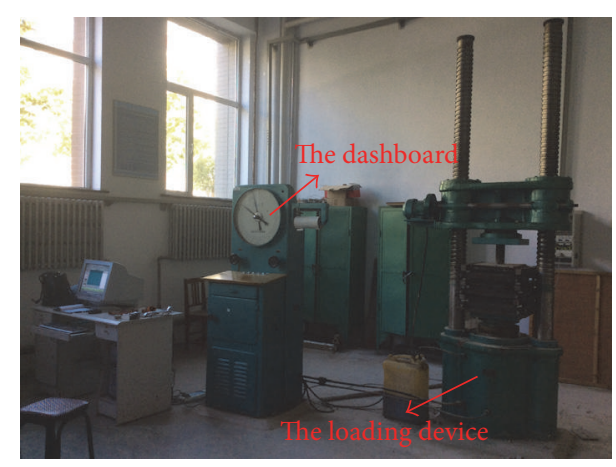

Figure 4: System of electric-hydraulic servo test machine.

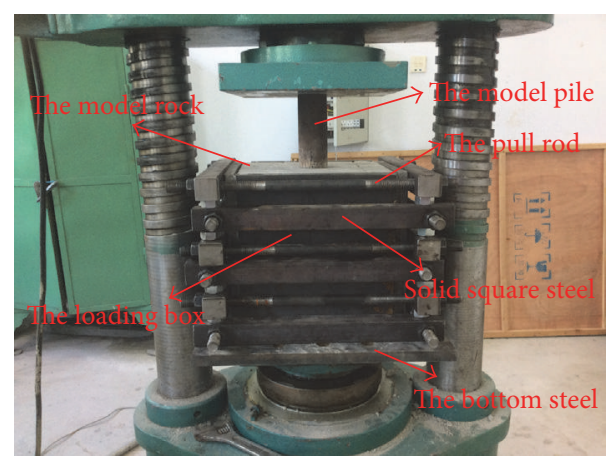

FIGURE 5: The loading box.

(the cutting blocks) was put into the loading box. It was necessary to ensure that the rock surface was horizontal and the pile body would not decline during loading. Taking into consideration the influence of the different jointed distribution angles on the failure mode of the rock, the model test used three groups of rock models with different strength. Each group of rock models contained intact rock and jointed rock with angle of $0^{\circ}, 10^{\circ}, 30^{\circ}, 45^{\circ}, 60^{\circ}, 75^{\circ}$ and $90^{\circ}$, respectively, as shown in Figures 6(a) and 6(b).

3.2.3. Loading Method and Data Collection. The test adopted a rapid loading method, which means that the pile end is under sustained loading until the bedrock fails. The measurement data for displacements and settlements were recorded during the process of loading. The displacement was measured by a displacement transducer fixed on the top of the pile. Loading termination occurred when one of the following conditions was noted: (1) under a certain load level, the model appears unstable; (2) the displacement of pile body increases suddenly; or (3) the values recorded by the measuring instruments no longer change.

\section{Comparative Analysis of the Testing Results and Numerical Calculating Results}

4.1. Crack Distribution and the Load Transferring Mode. According to the testing results, the crack distribution and development are related to the jointed dip angles. The testing results were recorded when the jointed dip angles were $0^{\circ}$, $10^{\circ}, 30^{\circ}, 45^{\circ}, 60^{\circ}, 75^{\circ}$, and $90^{\circ}$, respectively. As can be seen in Figure 7 , the cracks increased gradually in relation to increase in axial pressure. When the bedrock is intact, as shown in Figure $7(\mathrm{a})$, the cracks form in a radial distribution; when the bedrock has a jointed angle of $0^{\circ}$ to $10^{\circ}$, as shown in Figures 7 (b) and 7(c), there is no obvious influence on rock failure; when the jointed angle is $30^{\circ}$ to $45^{\circ}$, as shown in Figures $7(\mathrm{~d})$ and $7(\mathrm{e})$, the number of cracks is significantly reduced compared with the model with the angle of $0^{\circ}$, and the cracks are mainly concentrated near the joint surfaces. The number of cracks is also reduced when the jointed angle is $60^{\circ}$ to $75^{\circ}$, as shown in Figures $7(\mathrm{f})$ and $7(\mathrm{~g})$, and the rock failure is caused by the sliding of the jointed surfaces. The failing process is sharp and does not feature the propagation and accumulation process of new cracks. When the jointed angle is $90^{\circ}$, as shown in Figure $7(\mathrm{~h})$, the loading direction is parallel to the joint, and the crack distribution is basically symmetrical. This means that the existence of joints does not change the failure mode of the bedrock in this condition, and the rock failure is caused by the loading of the pile end and the sliding of the jointed surface. So when the jointed dip angle is small, less than $30^{\circ}$, there is no obvious effect on the failing mode of the bedrock. When jointed angle becomes large, between $30^{\circ}$ and $75^{\circ}$, the existence of joints changes the failure mode of the bedrock, and the crack distribution becomes asymmetrical. When a jointed angle is parallel to the loading direction, crack propagation results from the compression of the rock mass. The testing data show that the results of the numerical simulation are in good agreement with ones of the modeling test.

In general, the deformation of the jointed rock surface plays a controlling role in the total failure state. Comparisons of the initial state and failing state of the model rock with different jointed angles show that there is no obvious change in the jointed surface of $0^{\circ}$ after failure. That is to say, when the jointed surface is perpendicular to the loading direction, the influence of the joints on the rock foundation is very small, almost negligible. However, it can be found that when the jointed dip angles are $45^{\circ}, 60^{\circ}$, or $75^{\circ}$, the sliding phenomenon along the jointed surface is obvious, especially at a jointed angle of $60^{\circ}$.

4.2. The Wedge Failing Forming. The load-carrying mechanism of the pile can be regarded as a local compression problem when the load is on the top of the pile and the weight of the overlying soil layer is relatively small. The failing process of the intact bedrock is shown in Figure 8. Firstly, the upper load is transferred to the end of the pile, and the rock mass under the pile is continuously pressed until it is crushed. Under sustained loading, the interface of the pile and the rock generates shear force. When the shear stress exceeds the shear strength, the rock will fail along a rupture angle $(\theta)$. At this point, a wedge failing form appears in the rock at the pile end, and the wedge splitting failure of the bedrock is produced under the local pressure load. However, the shape of the wedge differs according to the different dip angles. As shown in Figure 9, the jointed dip angles are, respectively, $0^{\circ}$ and $75^{\circ}$. It is obvious that the height of the wedge becomes smaller 


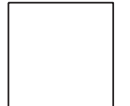

No joints

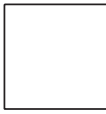

No joints

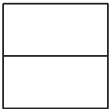

$0^{\circ}$

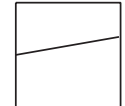

$10^{\circ}$

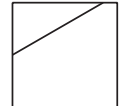

$30^{\circ}$

(a)

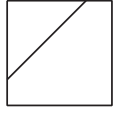

$45^{\circ}$

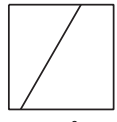

$60^{\circ}$
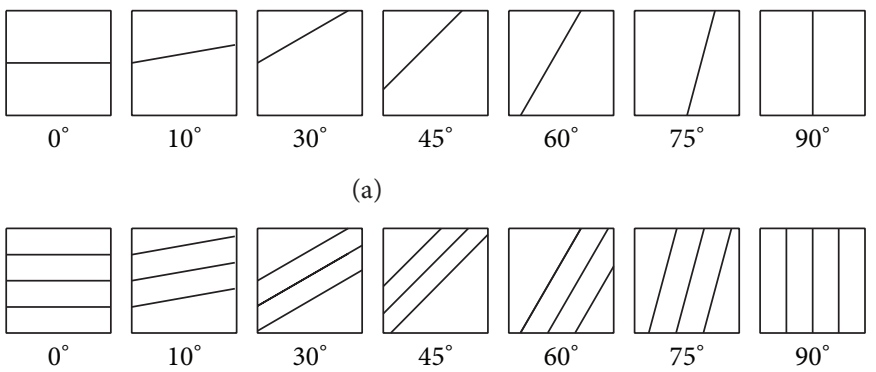

$10^{\circ}$

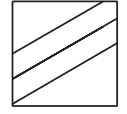

$30^{\circ}$
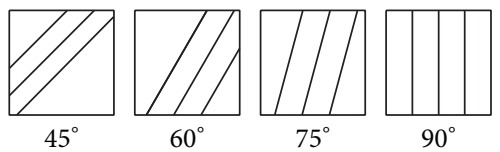

(b)

FIgURE 6: The distributions of single joints and a set of joints.

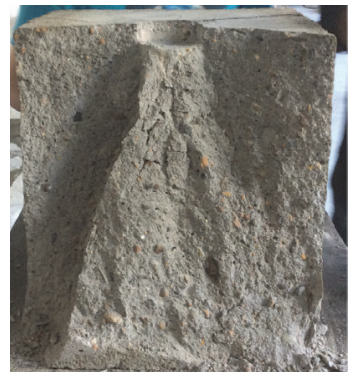

(a) No joints

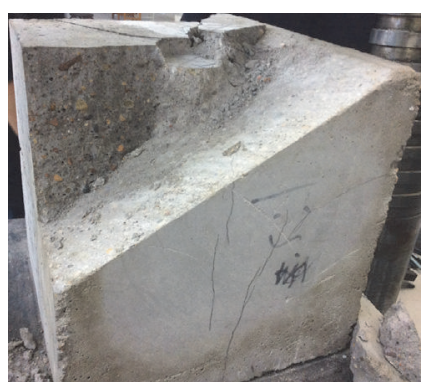

(d) $30^{\circ}$

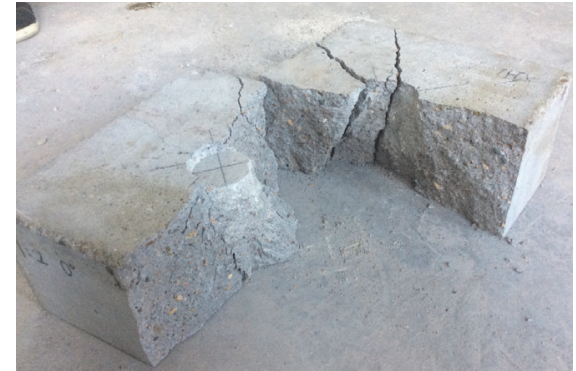

(b) $0^{\circ}$

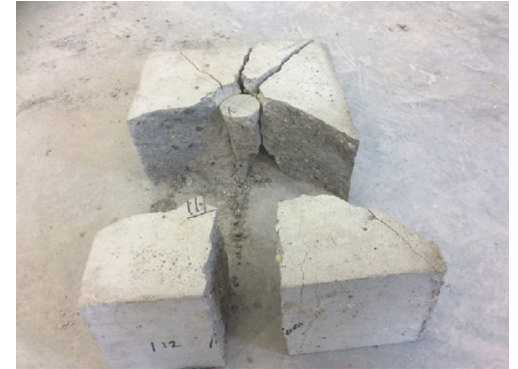

(c) $10^{\circ}$

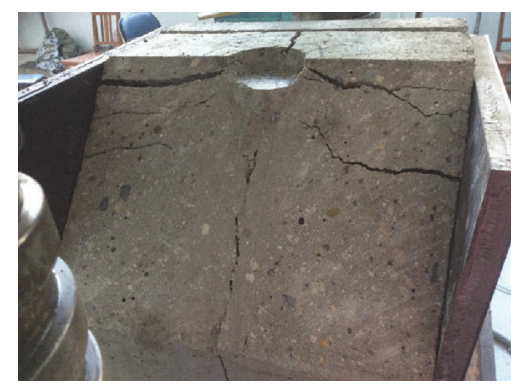

(e) $45^{\circ}$

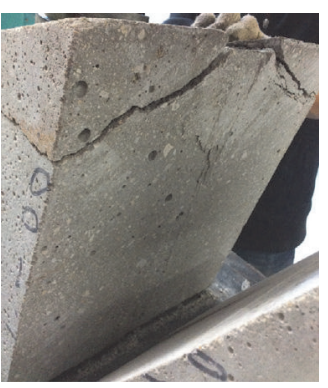

(f) $60^{\circ}$

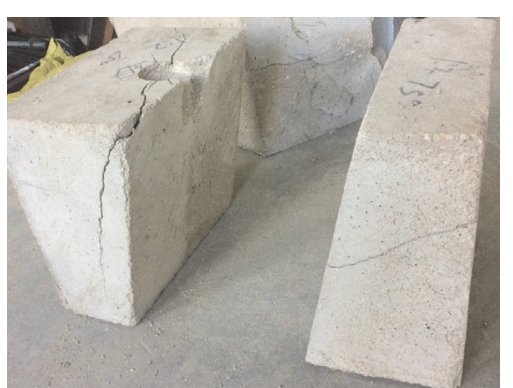

(g) $75^{\circ}$

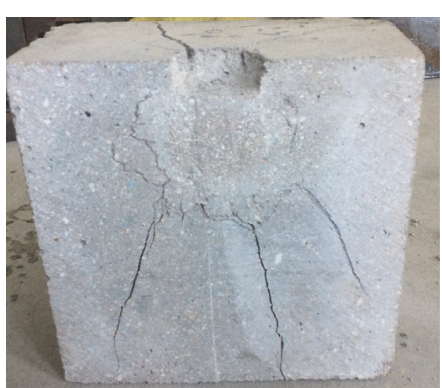

(h) $90^{\circ}$

FIGURE 7: The testing crack distributions of single-jointed rock mass with different dip angles.

as the jointed inclination angle increases and the shape of the wedge is asymmetrical, which is caused by the uneven distribution of the shear stress at the end of the pile.

4.3. Force-Displacement Curves (Q-S Curves). In general, the ultimate end bearing capacity is determined when the displacement of the pile top corresponds to the pile diameter by $10 \%$. However, the pile diameters in this model test are extremely small, and the calculated value is less than $9 \mathrm{~mm}$. Given that the model pile is different from the pile in practical engineering, the final loading value of the pile top is used to represent the bearing capacity of a single pile. In the early stage of loading, the joints of the rock experienced the process of closure regardless of the size of the dip angle. 

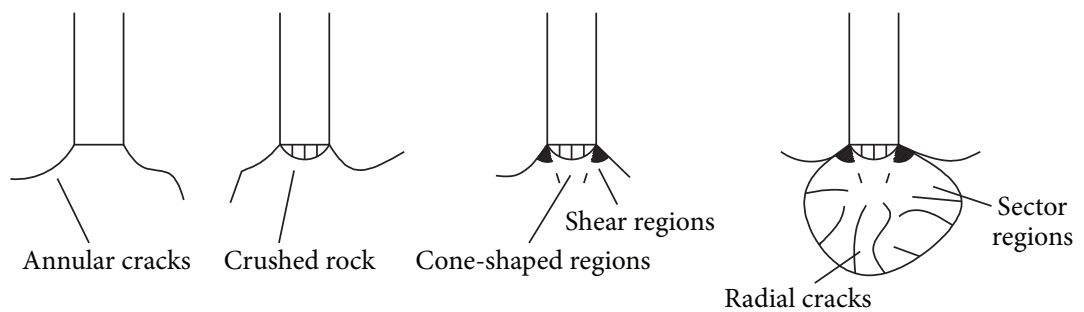

FIGURE 8: The failure process of the intact rock foundation.

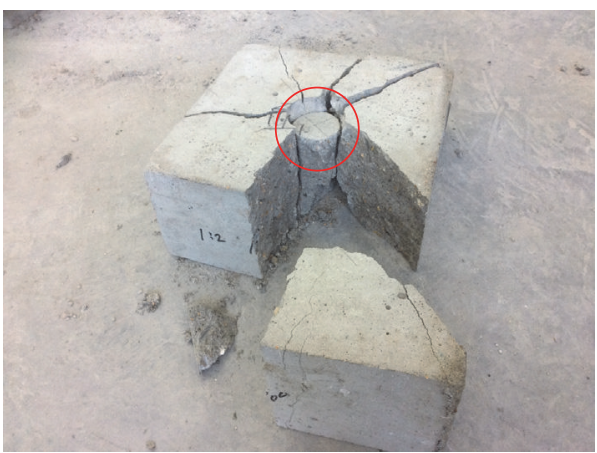

(a)

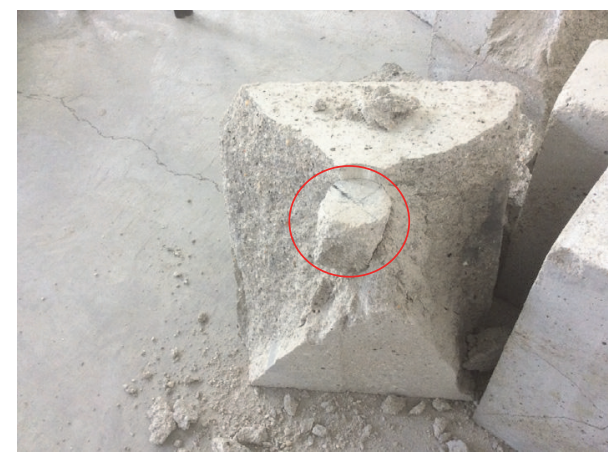

(b)

FIGURE 9: The wedge failing forming.

Thus the curves of the load and displacement have shown a nearly linear relationship and gradually change to a nonlinear relationship as the rock becomes deformed, and there are obvious turning points in the Q-S curves as shown in Figures 10 and 11.

The deformation of the jointed rock mass can be divided roughly into the following four phases: (1) structural adjustment and jointed closure: the original cracks and the joints are closed, and the rock is compressed to format the early nonlinear deformation. (2) Elastic deformation and crack stable development: the curve of this phase is similar to the linear phase, and, according to the deformation mechanism, it can be subdivided into the elastic phase and the stable developing phase of micro cracking. (3) Unstable development: the strength of the joint reaches the ultimate strength, and relative sliding occurs at the jointed surfaces and microcracks continue to develop. Due to the effect of the stress concentration caused by the cracking process, cracking will continue to develop even if the external load remains constant. (4) Destruction: when the bedrock reaches the ultimate bearing capacity, its internal structure is destroyed. In this phase, cracks develop rapidly and form macroscopic cracks. At this point, rock deformation manifests mainly in the relative sliding of rock blocks along the surface of the macro cracks, and the bearing capacity decreases as deformation increases. Even so, the load value is never reduced to zero, since it is clear that the jointed rock mass still has some bearing capacity. As seen from the entire curve, for example, of Figure 10(f), the rock mass reaches the ultimate load relatively slowly, but the failing rock mass retains some residual stress because of the structural effect.
The test can also help obtain the relationship between the different jointed dip angles and the end bearing capacity of the rock. As the jointed dip angles increase from $0^{\circ}$ to $90^{\circ}$, the settlement for the pile end first increases and then decreases under the same load. For example, when the load is $200 \mathrm{KN}$ the settlements of the pile end for the jointed bedrock models of group A, as shown on Figure 10 , are $3.6 \mathrm{~mm}, 3.8 \mathrm{~mm}$, $3.9 \mathrm{~mm}, 4.3 \mathrm{~mm}, 6.5 \mathrm{~mm}, 6.3 \mathrm{~mm}$, and $6.1 \mathrm{~mm}$ and $4.0 \mathrm{~mm}$. The results indicated that the existence of the joints made the settlement of the pile end. And the phenomenon is more obvious when the jointed dip angles are $45^{\circ}, 60^{\circ}$, and $75^{\circ}$ as seen in Figures 10(e), 10(f), and 10(g). In fact, the increments of jointed bedrock include two parts: the compression of rock and the slip of joint surface. When the jointed dip angles are $45^{\circ}, 60^{\circ}$, and $75^{\circ}$, the increments caused by the slip of joined surface are increased. And the Q-S curves of Figure 11 show the same phenomenon as in Figure 10. But when the jointed dip angles are $90^{\circ}$ the existence of the joints has no obvious influence on the settlement of pile end.

From Figures 10 and 11, it can be found that the settlements of three-single-joint rock are larger than that of a joint rock when the load is same. The deformation characteristics of the jointed rock mass can be obtained by comparing the Q-S curves such as a single joint of $45^{\circ}$ (Figure 10(e)) and three joints of $45^{\circ}$ (Figure 11(e)). The shapes of the Q-S curves before reaching the peak strength are approximately the same for the single joint bedrock and the single set of multiple joints bedrock, but the slope for the single-jointed rock is larger than that for the three-jointed rock, which shows that the deformation capacity of the single-jointed rock mass is better than that of the single set of jointed rock mass. This 
$\mathrm{Q}(\mathrm{kN})$

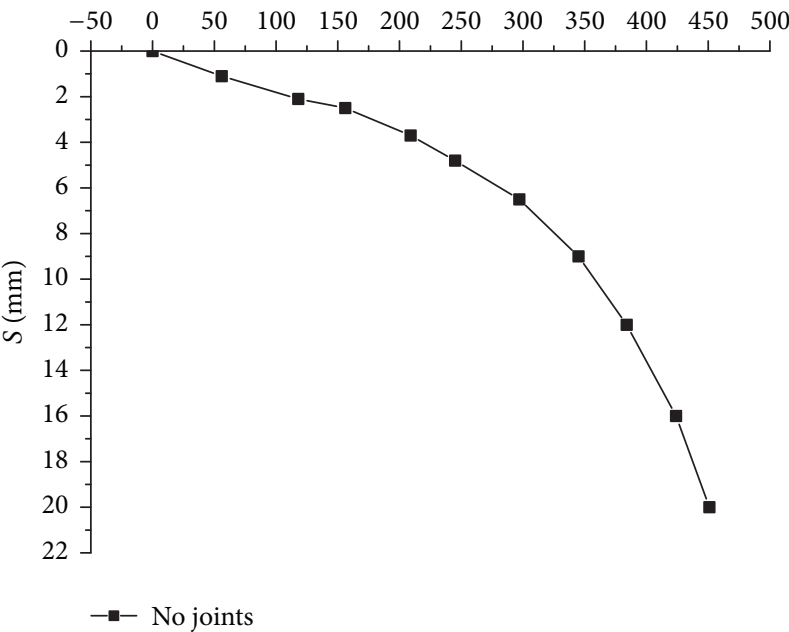

(a) No joints

$\mathrm{Q}(\mathrm{kN})$

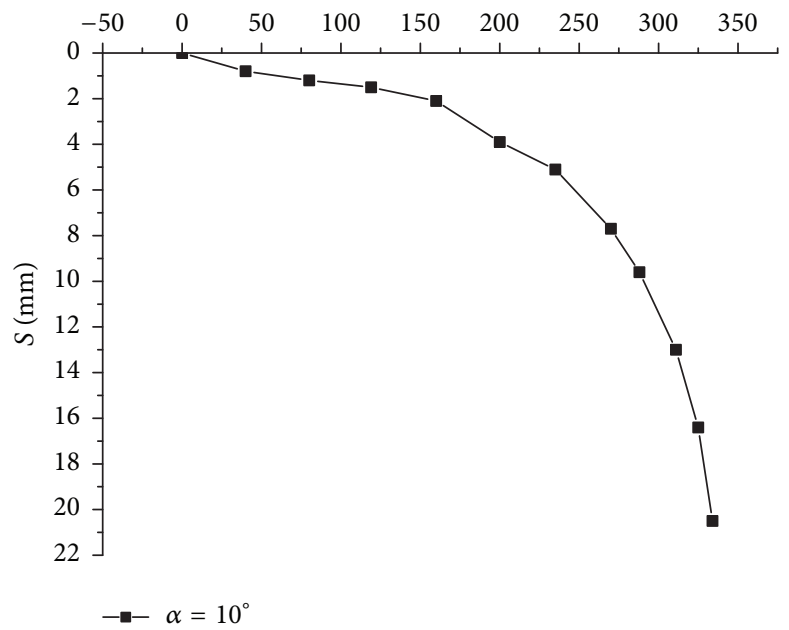

(c) $10^{\circ}$

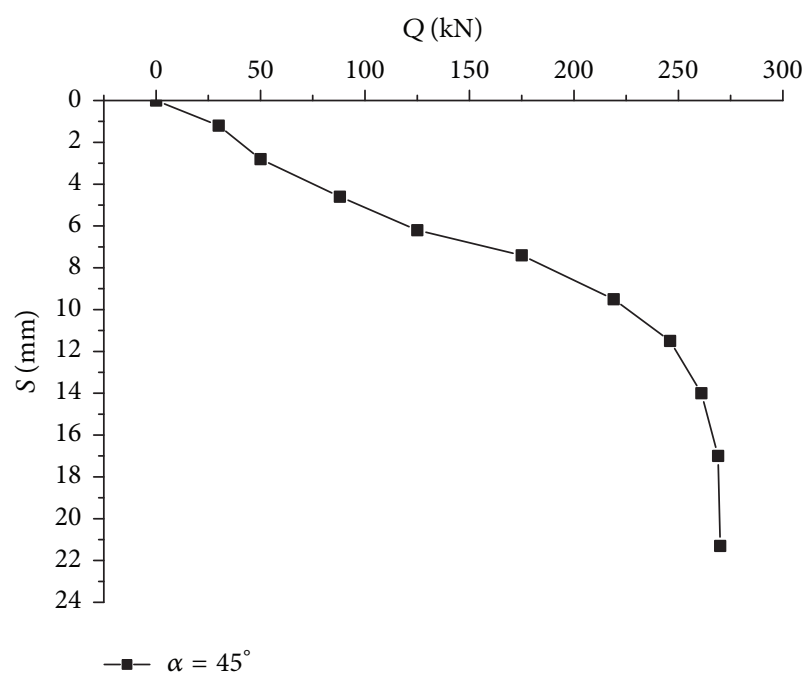

(e) $45^{\circ}$

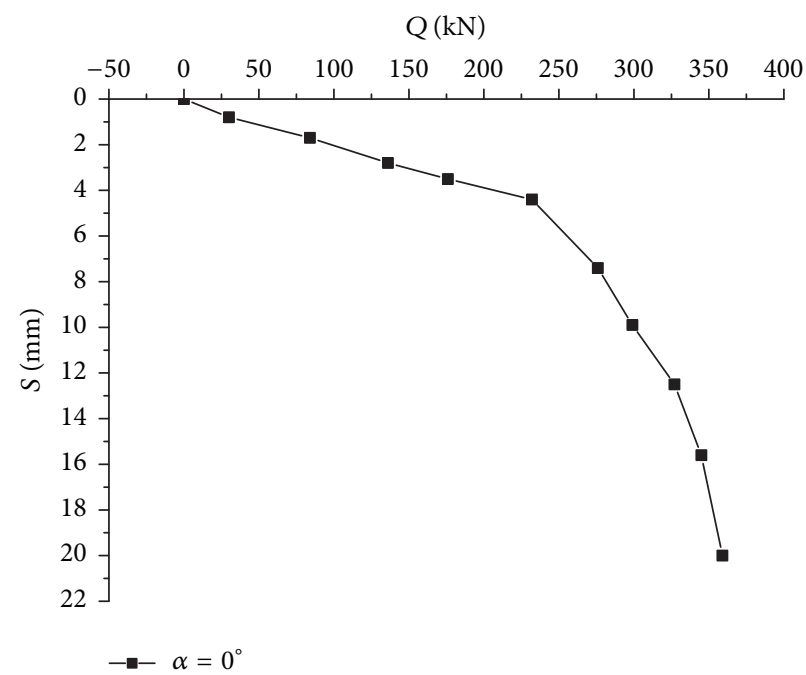

(b) $0^{\circ}$

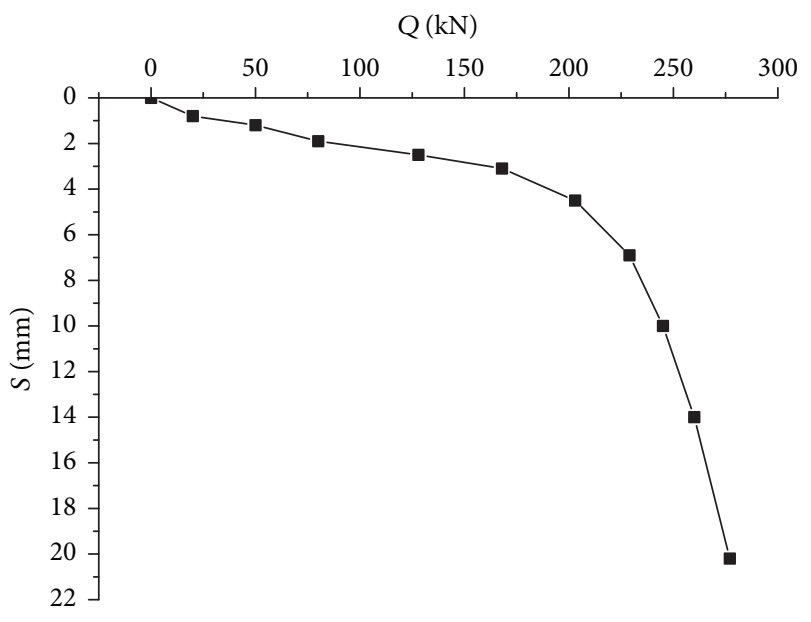

(d) $30^{\circ}$

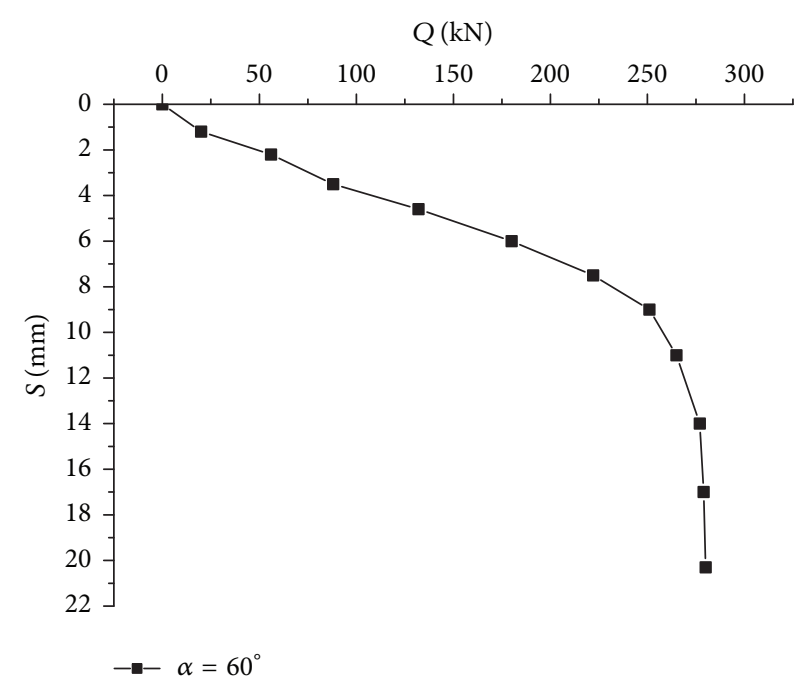

(f) $60^{\circ}$

FIGURE 10: Continued. 


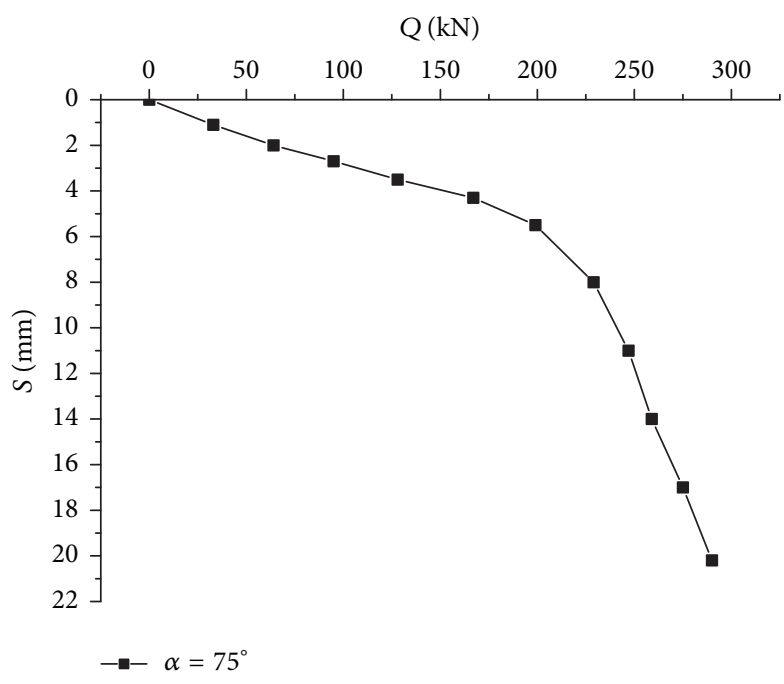

(g) $75^{\circ}$

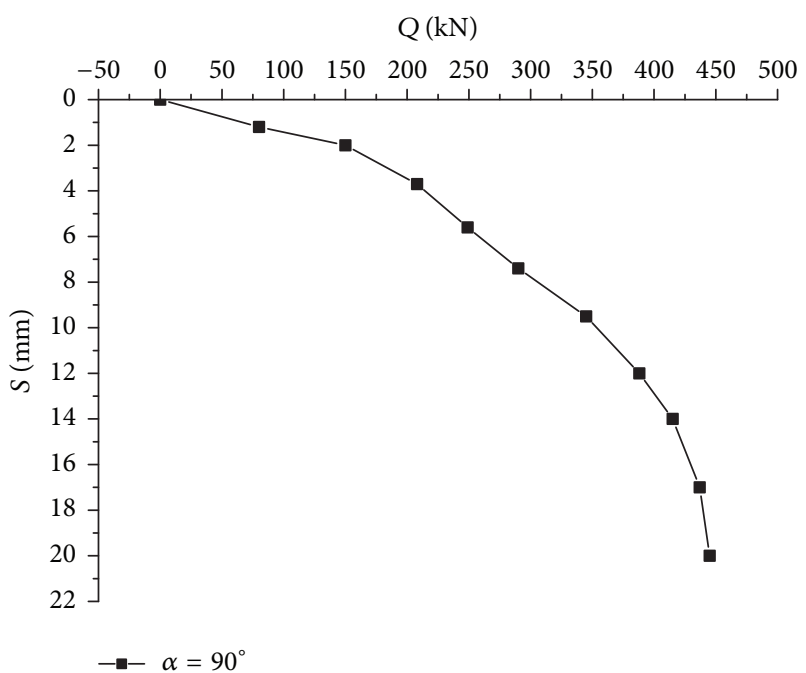

(h) $90^{\circ}$

FIGURE 10: The Q-S curves of a single pile for group A.

also indicates that the ultimate bearing capacity of the singlejointed rock mass is much better than that of the three-jointed rock mass.

In addition, the $Q-S$ curves for intact bedrock are shown as in Figure 12(a) and the Q-S curves for jointed bedrock with the dip angle of $45^{\circ}$ are shown as in Figure 12(b). The Q-S curves show that the simulating results are in good agreement with the testing results. It also shows that the discrete element method can simulate the end bearing behavior of the jointed bedrock.

\subsection{Load-Bearing Characteristic}

4.4.1. The Effect of the Rock Strength on the Ultimate End Bearing Capacity. In order to determine the relationship between the ultimate end bearing capacity of the pile and the rock strength the data obtained in the test were plotted, as shown in Figure 13, where the whole curve shows a "V" shape. And the order for end bearing capacity of the jointed rock mass of group A from being high to low is those with the dip angles of $90^{\circ}, 0^{\circ}, 30^{\circ}, 45^{\circ}, 60^{\circ}$, and $75^{\circ}$, respectively; the order for end bearing capacity of the jointed rock mass of group B from being high to low is those with dip angles of $0^{\circ}$, $90^{\circ}, 30^{\circ}, 45^{\circ}, 60^{\circ}$, and $75^{\circ}$, respectively. The comparison of the bearing behavior of the pile end with the intact bedrock shows that the existence of joints reduces the end ultimate bearing capacity regardless of the arrangement of the joint dip angles. The ultimate end bearing capacity of the intact rock is $415 \mathrm{KN}$ from the test result. And the ultimate end bearing capacity of jointed rock at a $45^{\circ}$ angle is $268 \mathrm{KN}$, which is a reduction of $35.4 \%$. These results also indicate that the existence of joints in the rock foundation leads to significant anisotropy. Moreover, the strength of the rock decreases in the presence of joints even if the jointed surface is perpendicular to the direction of maximum principal stress. However, the effect of horizontal joints on the strength of the rock is not accidental; rather, it can be attributed to the friction and the binding effect of the jointed surface.

Comparing the different strengths of the bedrock in group A and group B, the rock strength clearly has an influence on the end bearing capacity, namely, that the ultimate end bearing capacity increases as the rock strength increases when the jointed dip angle is determined. It can be seen from Figure 13 that no matter how much the jointed dip angle is the end bearing capacity of group A is greater than that of group B. The reason is that the increasing of rock strength could increase the ability of the bedrock to resist upper load to a certain extent. But when the jointed angles of the bedrock are $45^{\circ}, 60^{\circ}$, and $75^{\circ}$, the end bearing capacity does not improve significantly with the increasing of rock strength, which indicates that the jointed dip angles of bedrock are the main influence factor to the end bearing capacity.

4.4.2. The Effect of the Jointed Number on the Ultimate End Bearing Capacity. Figure 14 shows that the ultimate bearing capacity of the pile end differs when the rock has the same jointed dip angles, but different jointed numbers. And the order for bearing capacity of the jointed rock mass of group $\mathrm{C}$ from being high to low is those with dip angles of $0^{\circ}, 90^{\circ}$, $30^{\circ}, 45^{\circ}, 60^{\circ}$, and $75^{\circ}$, respectively. The curves show that the same trend exists between single-jointed rock and multiplejointed rock, which still exhibits a "V" shape. But the end bearing capacity decreases as the jointed numbers increase. The reduction in strength is obvious when the number of joints increases from 1 to 3 , that is, from the rock with a single joint to the rock with multiple joints. The reason is that the increasing of the joints number of leads to the destruction of integrity of the bedrock. Furthermore, the anisotropy becomes more significant. 

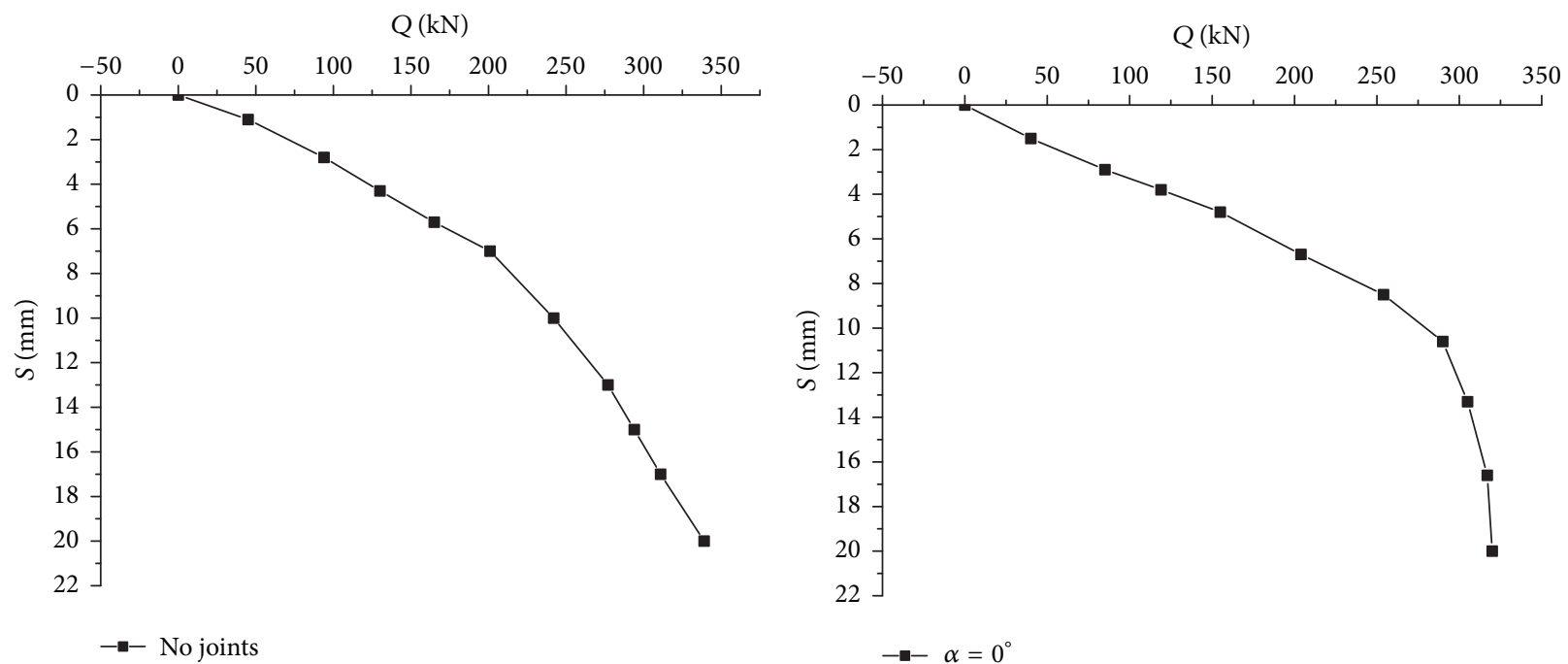

(a) No joints

(b) $0^{\circ}$
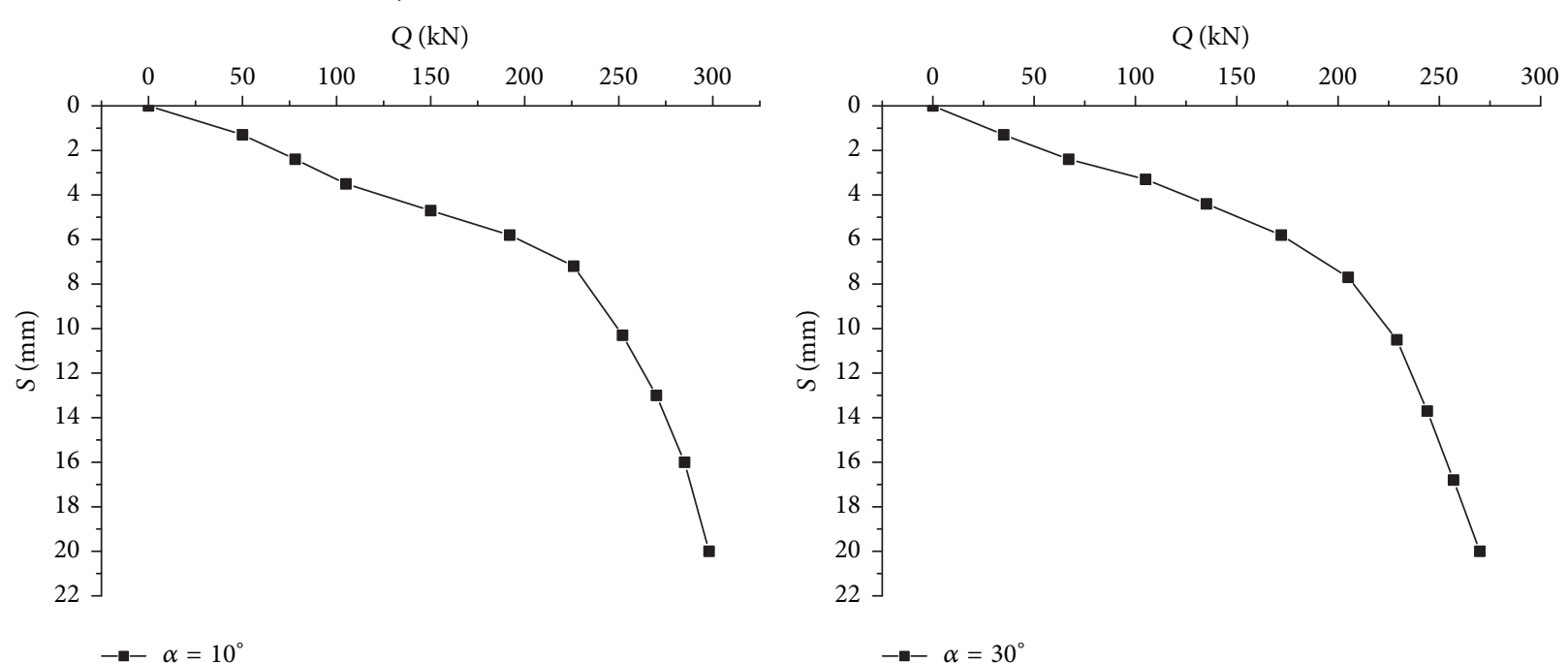

(c) $10^{\circ}$

(d) $30^{\circ}$
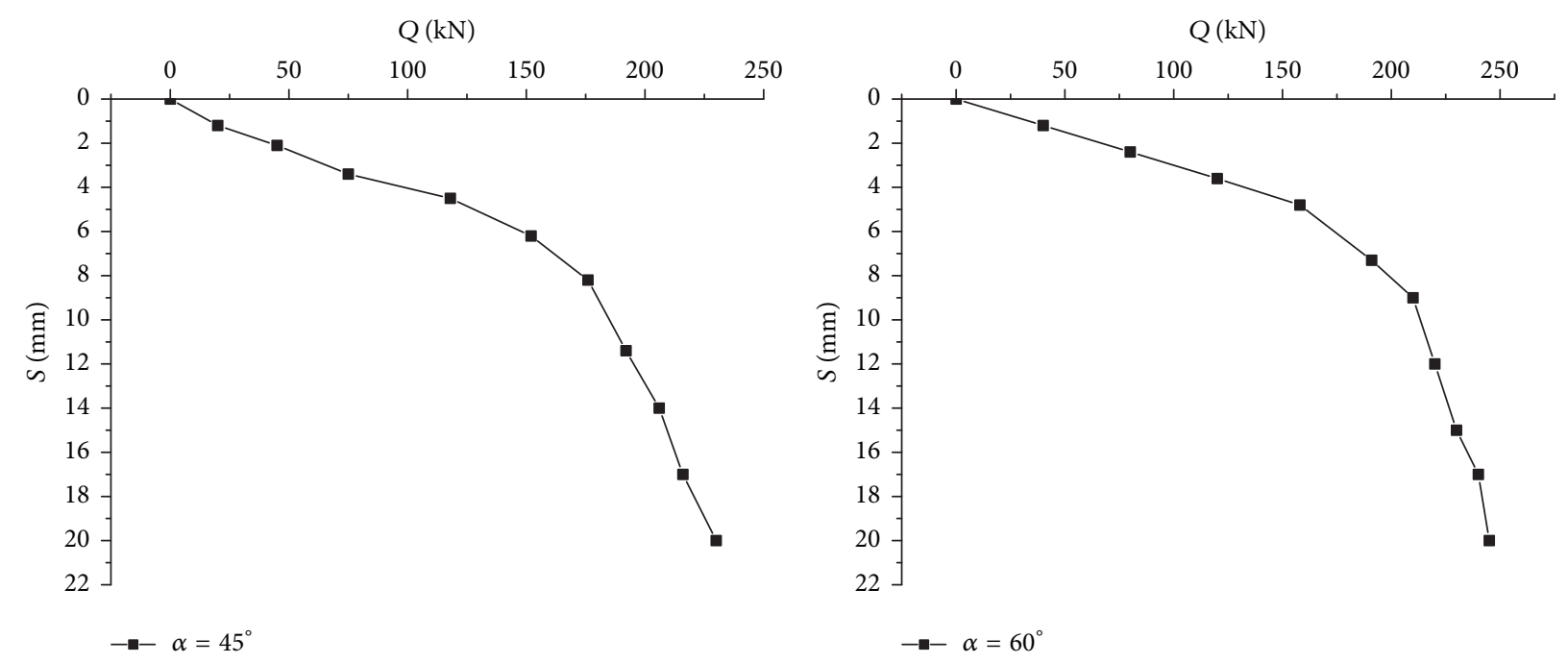

(e) $45^{\circ}$

(f) $60^{\circ}$

FIgURE 11: Continued. 


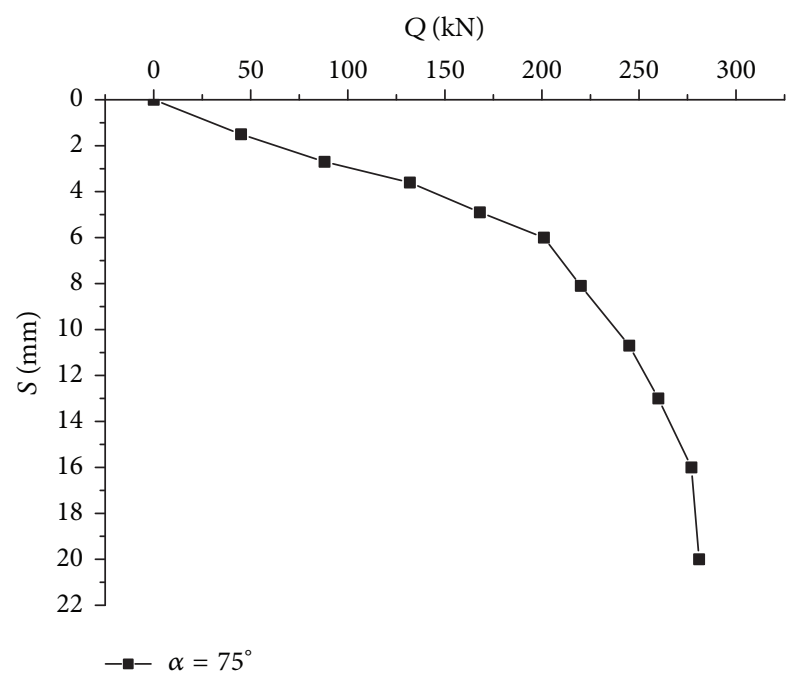

(g) $75^{\circ}$

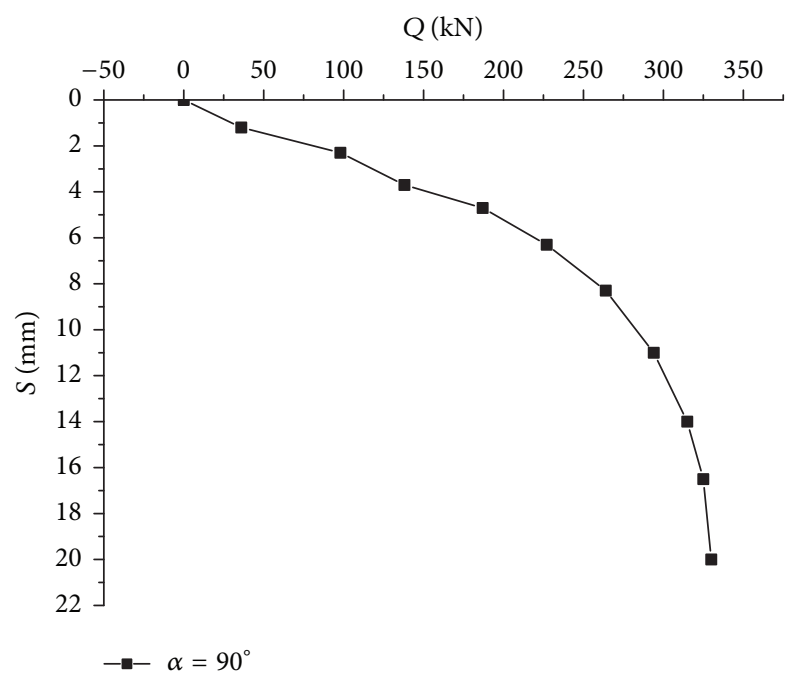

(h) $90^{\circ}$

FIGURE 11: The Q-S curves of a single pile for group C.

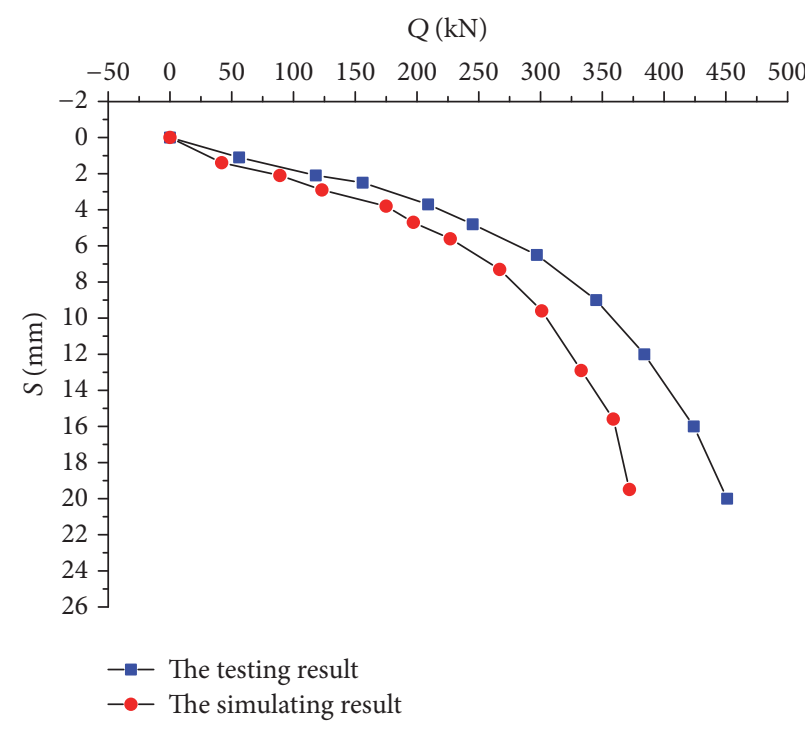

(a) The Q-S curves for intact bedrock

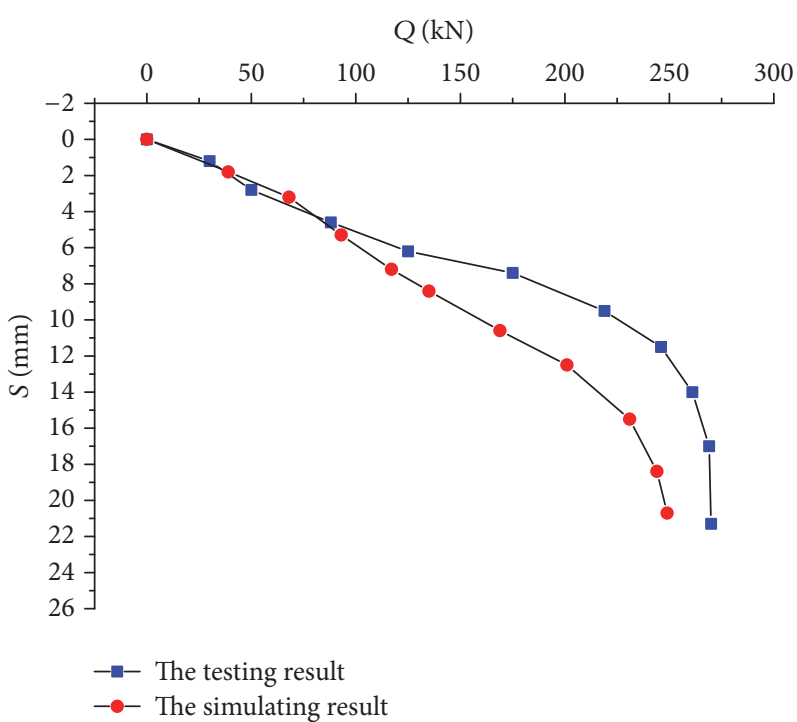

(b) The Q-S curves for jointed bedrock of $45^{\circ}$

FIGURE 12: The Q-S curves of the testing results and the simulating results.

\section{Conclusion}

Based on the above analysis about the intact rock foundation and the jointed rock foundation, the following conclusions can be drawn:

(1) The failure mode of the bedrock changes with the existence of the joints. The test results show that the jointed dip angles can change the crack distribution during the process of load transfer. When the jointed dip angle is small, less than $30^{\circ}$, the joints have no significant effect on the destruction of the bedrock; when the jointed dip angle becomes large, greater than $30^{\circ}$ and less than $75^{\circ}$, the cause of cracking includes rock compression and sliding of the jointed surfaces; and when the cracks are parallel to the direction of the dip angle, at $90^{\circ}$, the expansion of the cracks is mainly the result of rock compression.

(2) The load transfer path of the bedrock changes because of the joints. When the jointed dip angle is small, the change of the path is not obvious, but when the angle is between $45^{\circ}$ and $75^{\circ}$, the change is obvious.

(3) The wedge failing mode of the bedrock generally occurs at the pile end, and the shape of the wedge also changes according to changes in the joined dip angles.

(4) The overall shape of Q-S curves for jointed rock is approximately the same. However the direction 


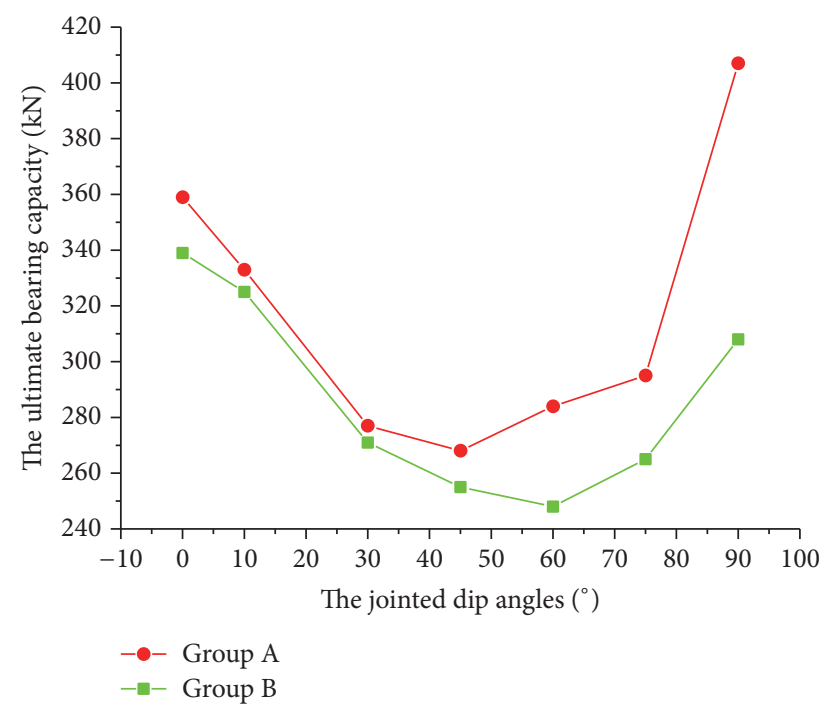

FIGURE 13: The curves for the ultimate bearing capacity of single pile under different rock strength.

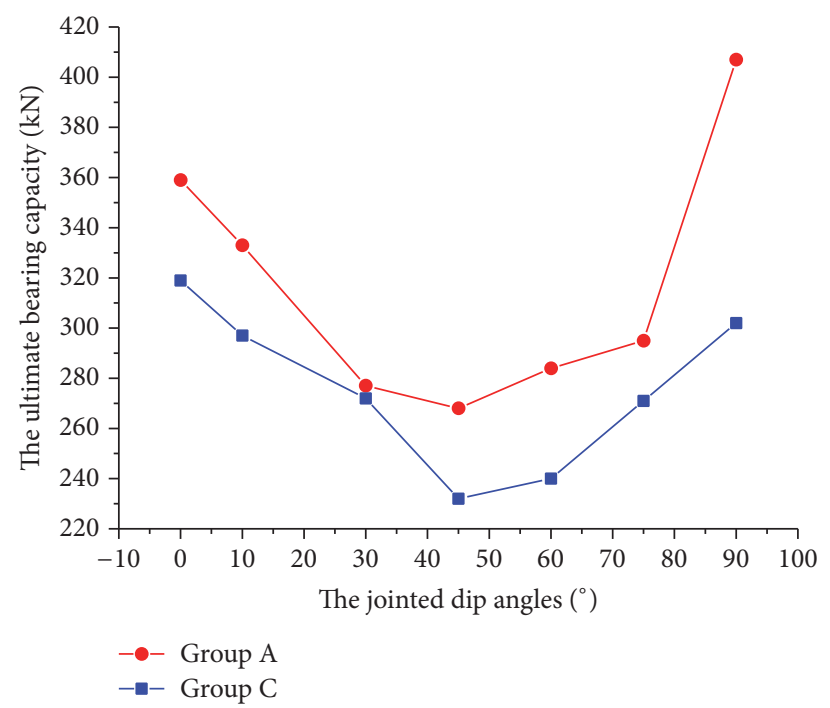

FIGURE 14: The curves for the ultimate bearing capacity of single pile under different jointed numbers.

and the turning point of the Q-S curves can change in response to changes in the jointed numbers and strength. The jointed angles affect the ultimate bearing capacity of the pile end, which increases as rock strength increases. However, when the jointed dip angle of the bedrock is $45^{\circ}$ and $60^{\circ}$, the end bearing capacity does not improve significantly, indicating that the jointed dip angles of the rock foundation are controlled mainly by the load-bearing capacity.

\section{Competing Interests}

The authors declare that they have no competing interests.

\section{Authors' Contributions}

For the research work, Jingwei Cai and Xinsheng Yin conceived and designed the experiments; Jingwei Cai, Xiaxin Tao, and Shibo Tao performed the experiments and analyzed the data; Xinsheng Yin and Aiping Tang contributed the test materials and analysis tools; Jingwei Cai wrote the paper.

\section{Acknowledgments}

This work was supported by a grant from National Natural Science Foundation of China (51178205).

\section{References}

[1] A. Serrano and C. Olalla, "Ultimate bearing capacity of an anisotropic discontinuous rock mass. Part I: basic modes of failure," International Journal of Rock Mechanics and Mining Sciences, vol. 35, no. 3, pp. 301-324, 1998.

[2] A. Serrano and C. Olalla, "Ultimate bearing capacity of an anisotropic discontinuous rock mass part II: determination procedure," International Journal of Rock Mechanics and Mining Sciences, vol. 35, no. 3, pp. 325-348, 1998.

[3] X.-L. Yang and J.-H. Yin, "Upper bound solution for ultimate bearing capacity with a modified Hoek-Brown failure criterion," International Journal of Rock Mechanics and Mining Sciences, vol. 42, no. 4, pp. 550-560, 2005.

[4] Z. Saada, S. Maghous, and D. Garnier, "Bearing capacity of shallow foundations on rocks obeying a modified Hoek-Brown failure criterion," Computers and Geotechnics, vol. 35, no. 2, pp. 144-154, 2008.

[5] M. Imani, M. Sharifzadeh, A. Fahimifar, and P. Haghparast, "A characteristic criterion to distinguish continuity of rock masses applicable to foundations," in Proceedings of the 45th US Rock Mechanics/Geomechanics Symposium, ARMA-11-508, San Francisco, Calif, USA, June 2011.

[6] G. Reik and M. Zacas, "Strength and deformation characteristics of jointed media in true triaxial compression," International Journal of Rock Mechanics and Mining Sciences \& Geomechanics Abstracts, vol. 15, no. 6, pp. 295-303, 1978.

[7] Z. Y. Yang, J. M. Chen, and T. H. Huang, "Effect of joint sets on the strength and deformation of rock mass models," International Journal of Rock Mechanics and Mining Sciences, vol. 35, no. 1, pp. 75-84, 1998.

[8] S. Q. Yang, Y. H. Dai, L. J. Han, and Z. Q. Jin, "Experimental study on mechanical behavior of brittle marble samples containing different flaws under uniaxial compression," Engineering Fracture Mechanics, vol. 76, no. 12, pp. 1833-1845, 2009.

[9] D. Mas Ivars, M. E. Pierce, C. Darcel et al., "The synthetic rock mass approach for jointed rock mass modelling," International Journal of Rock Mechanics and Mining Sciences, vol. 48, no. 2, pp. 219-244, 2011.

[10] X. P. Zhou, J. Bi, and Q. H. Qian, "Numerical simulation of crack growth and coalescence in rock-like materials containing multiple pre-existing flaws," Rock Mechanics and Rock Engineering, vol. 48, no. 3, pp. 1097-1114, 2015.

[11] F. Q. Gao and H. P. Kang, "Effects of pre-existing discontinuities on the residual strength of rock mass-insight from a discrete element method simulation," Journal of Structural Geology, vol. 85, pp. 40-50, 2016. 
[12] R.-H. Cao, P. Cao, H. Lin, C.-Z. Pu, and K. Ou, "Mechanical behavior of brittle rock-like specimens with pre-existing fissures under uniaxial loading: experimental studies and particle mechanics approach," Rock Mechanics and Rock Engineering, vol. 49, no. 3, pp. 763-783, 2016.

[13] J. Yang, G. Rong, D. Hou, J. Peng, and C. Zhou, "Experimental study on peak shear strength criterion for rock joints," Rock Mechanics and Rock Engineering, vol. 49, no. 3, pp. 821-835, 2016.

[14] Y. H. Huang, S. Q. Yang, W.-L. Tian, W. Zeng, and L.-Y. Yu, "An experimental study on fracture mechanical behavior of rocklike materials containing two unparallel fissures under uniaxial compression," Acta Mechanica Sinica, vol. 32, no. 3, pp. 442-455, 2016.

[15] F. H. Kulhawy and R. E. Goodman, "Design of foundations on discontinuous rock," in Proceedings of the International Conference on Structural Foundations on Rock, vol. 1, pp. 209220, Sydney, Australia, 1980.

[16] B. Benmokrane, K. S. Mouchaorab, and G. Ballivy, "Laboratory investigation of shaft resistance of rock-socketed piers using the constant normal stiffness direct shear test," Canadian Geotechnical Journal, vol. 31, no. 3, pp. 407-419, 1994.

[17] S. Maghous, P. de Buhan, and A. Bekaert, "Failure design of jointed rock structures by means of a homogenization approach," Mechanics of Cohesive-Frictional Materials, vol. 3, no. 3, pp. 207-228, 1998.

[18] D. J. Sutcliffe, H. S. Yu, and S. W. Sloan, "Lower bound solutions for bearing capacity of jointed rock," Computers and Geotechnics, vol. 31, no. 1, pp. 23-36, 2004.

[19] N. Halakatevakis and A. I. Sofianos, "Strength of a blocky rock mass based on an extended plane of weakness theory," International Journal of Rock Mechanics and Mining Sciences, vol. 47, no. 4, pp. 568-582, 2010.

[20] T. T. Yu, "The extended finite element method (XFEM) for discontinuous rock masses," Engineering Computations, vol. 28, no. 3, pp. 340-369, 2011.

[21] S. R. Hossein, M. Mohammad, and R. D. Morteza, "Distinct element simulation of ultimate bearing capacity in jointed rock foundations," Arabian Journal of Geosciences, vol. 6, no. 11, pp. 4427-4434, 2013. 


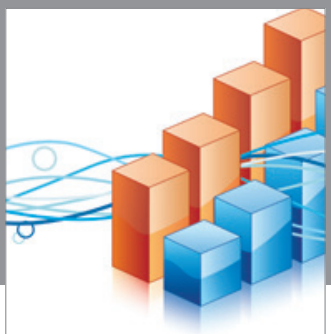

Advances in

Operations Research

vatem alat4

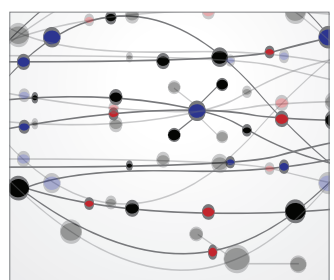

\section{The Scientific} World Journal
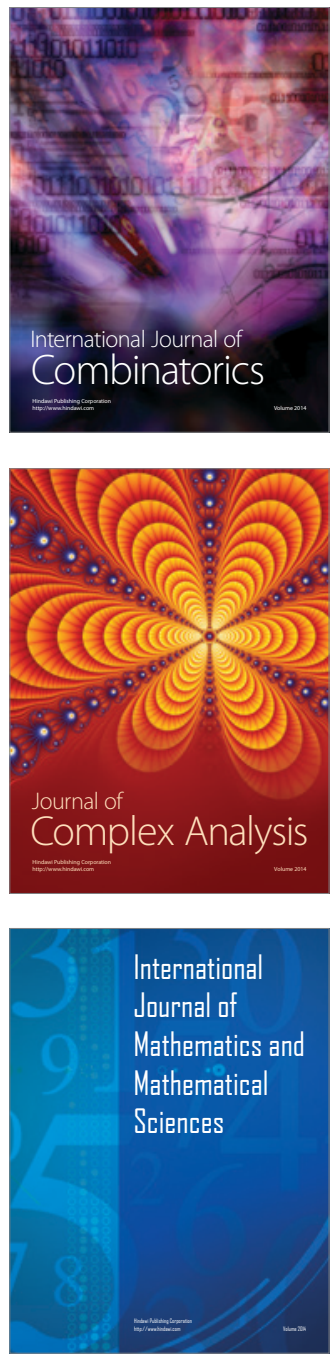
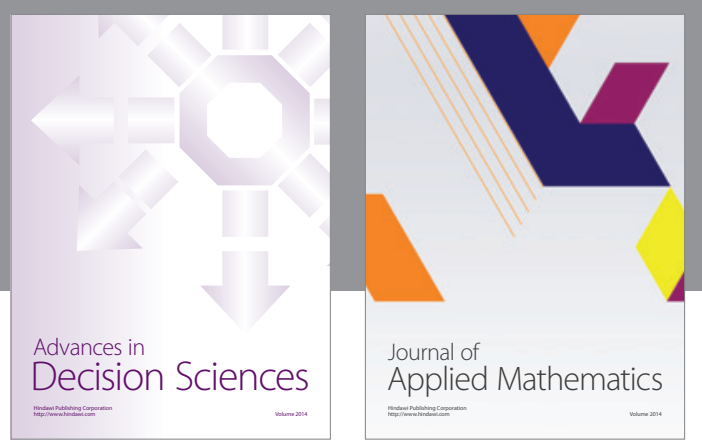

Algebra

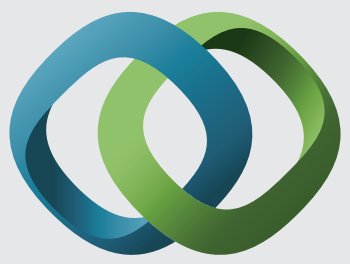

\section{Hindawi}

Submit your manuscripts at

http://www.hindawi.com
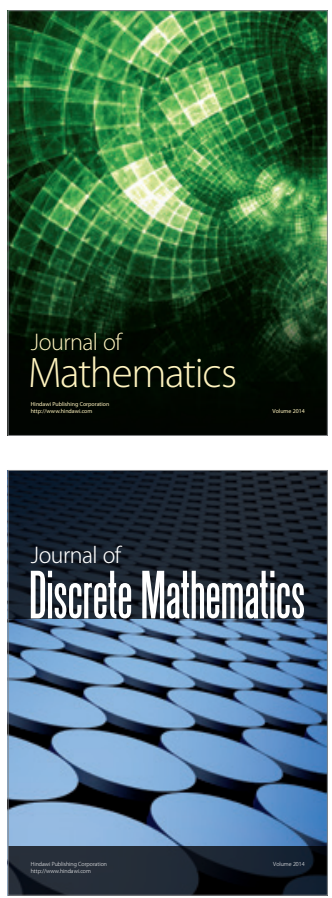

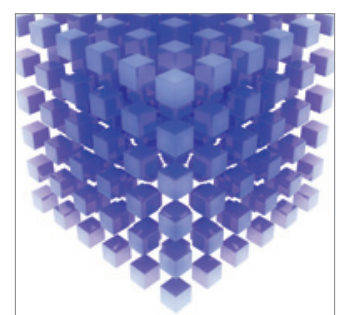

Mathematical Problems in Engineering
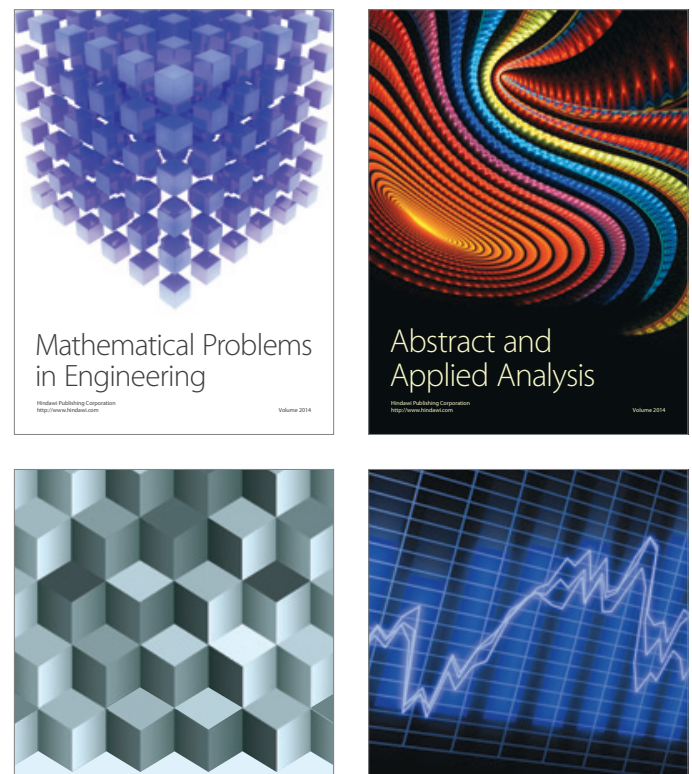

Journal of

Function Spaces

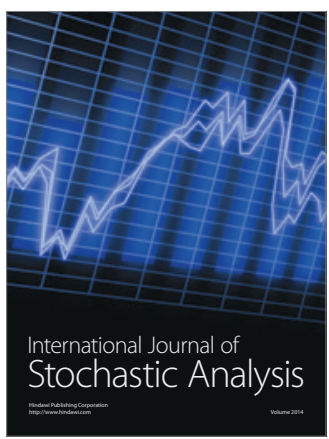

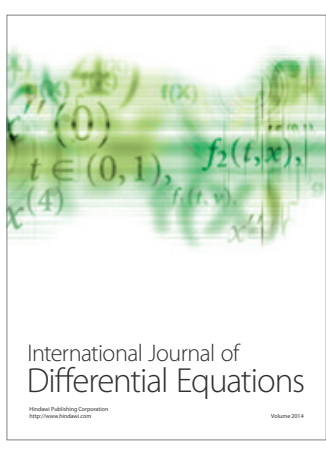
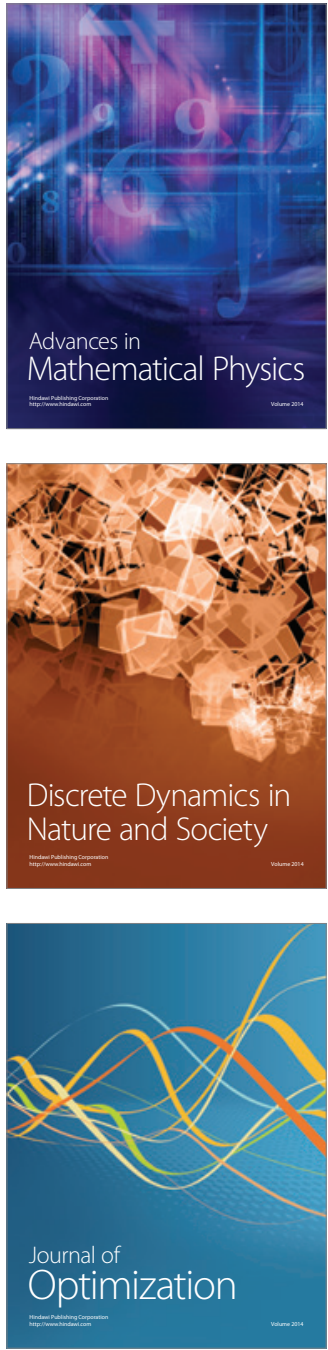